\title{
Customer Metrics and Their Impact on Financial Performance
}

\author{
Sunil Gupta \\ Harvard Business School, 179 Morgan, Soldiers Field, Boston, Massachusetts 02163, sgupta@hbs.edu \\ Valarie Zeithaml \\ Kenan-Flagler School of Business, University of North Carolina at Chapel Hill, 4207 McColl, North Carolina 27599, \\ valariez@unc.edu
}

\begin{abstract}
$\mathrm{T}$ he need to understand the relationships among customer metrics and profitability has never been more critical. These relationships are pivotal to tracking and justifying firms' marketing expenditures, which have come under increasing pressure. The objective of this paper is to integrate existing knowledge and research about the impact of customer metrics on firms' financial performance. We investigate both unobservable or perceptual customer metrics (e.g., customer satisfaction) and observable or behavioral metrics (e.g., customer retention and lifetime value). We begin with an overview of unobservable and observable metrics, showing how they have been measured and modeled in research. We next offer nine empirical generalizations about the linkages between perceptual and behavioral metrics and their impact on financial performance. We conclude the paper with future research challenges.

Key words: customer satisfaction; service quality; customer lifetime value; customer retention; customer equity; profitability; firm value

History: This paper was received August 19, 2004, and was with the authors 14 months for 2 revisions; processed by William Boulding.
\end{abstract}

\section{Introduction}

Customers are the lifeblood of any organization. Without customers, a firm has no revenues, no profits and therefore no market value. This simple fact is not lost on most senior executives. In a worldwide survey of 681 senior executives conducted by The Economist during October-December 2002, 65\% of the respondents reported customers as their main focus over the next three years compared to only $18 \%$ who reported shareholders as their main focus (The Economist 2003). Oddly enough, while senior executives recognize the importance of customers, they still rely heavily on financial measures because customer metrics are not clearly defined (Ittner and Larcker 1996).

In this paper, we review and integrate existing knowledge on customer metrics (e.g., customer satisfaction, retention) and provide several generalizations about their impact on the financial performance of firms. As marketing strives for greater accountability, it is critical that we understand how customer metrics link to profitability and firm value. This paper has three objectives: (a) to provide a review of key customer metrics and the measurement and modeling issues related to them, $(b)$ to highlight generalizable findings about the links between customer metrics and financial performance of a firm, and (c) to suggest areas for future research.

Customer metrics include a variety of constructs. We categorize them into observable or behavioral and unobservable or perceptual measures. Observable measures involve behaviors of customers that typically relate to purchase or consumption of a product or service. From a customer's perspective, these include decisions of when, what, how much, and where to buy a product. From a firm's perspective, this translates into decisions about customer acquisition, retention, and lifetime value. Unobservable constructs include customer perceptions (e.g., service quality), attitudes (e.g., customer satisfaction), or behavioral intentions (e.g., intention to purchase). In economists' terminology, unobservable constructs are stated preferences, while observable constructs are revealed preferences.

Intuitively, unobservable constructs are related to observable behavior, which leads to financial gains. Satisfaction, for example, is expected to lead to repurchase behavior, which translates into increased sales and profits. In Figure 1, we suggest a simple framework to link what firms do (i.e., their marketing actions), what customers think (i.e., unobservable constructs), what customers do (i.e., behavioral outcomes), and how customers' behavior affects firms' 
Figure 1 Framework for Customer Metrics and Their Impact on Firms' Financial Performance

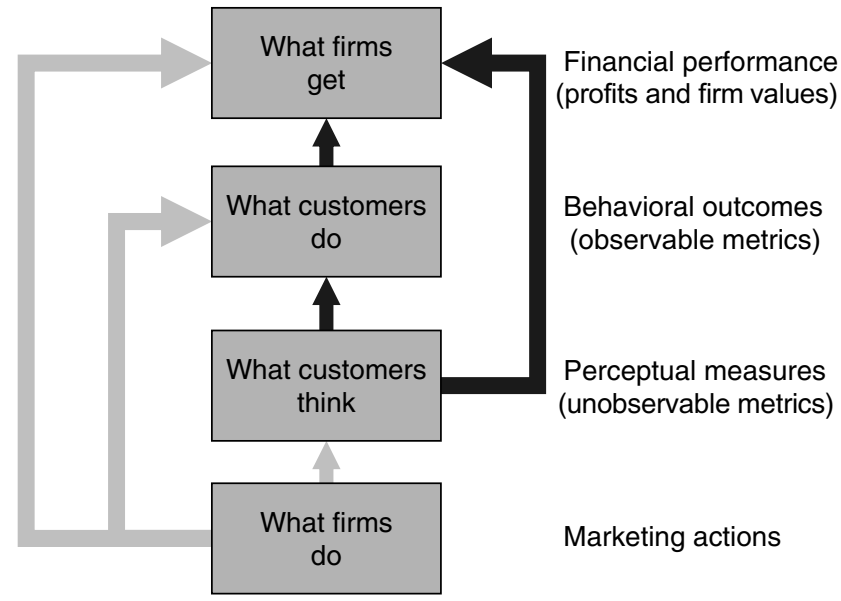

Note. The links and arrows in black are the focus of this study.

financial performance (i.e., profits and firm value). ${ }^{1}$ Most research studies on these topics either investigate relationships in one of the boxes, or at best link relationships between constructs in two of the boxes. For example, some studies have established a link between unobservable constructs (e.g., satisfaction) and firm value, but do not consider intervening behavioral outcomes. Several researchers have also established a direct link between marketing actions and firms' financial performance (e.g., Joshi and Hanssens 2005) without examining antecedents in the black box, the term used by many researchers for the unobservable constructs. Given the vast literature in this field, we will focus on three links: (a) impact of unobservable constructs on financial performance (e.g., link between satisfaction and profitability), (b) impact of unobservable constructs on observable constructs (e.g., link between satisfaction and retention), and (c) impact of observable constructs on financial performance (e.g., link between retention and profitability).

The paper is organized to reflect relationships indicated in Figure 1. In $\S 2$, we begin by describing key unobservable and perceptual customer metrics. For each construct, we briefly discuss how it has been defined and measured. In §3, we describe key observable customer metrics and the modeling issues surrounding them. Section 4 describes main findings from research that links unobservable metrics to financial performance. Research results about the link between unobservable and observable metrics are discussed in $\$ 5$. Section 6 discusses findings that focus on linking observable metrics to financial performance. In §7, we identify unresolved issues and

\footnotetext{
${ }^{1}$ Market and competitor factors are implicit in Figure 1.
}

suggest directions for future research. We conclude in $\S 8$.

\section{Unobservable or Perceptual Customer Metrics}

Concepts in the black box-the unobservable concepts-have been studied extensively for many reasons. First, because they are collected almost exclusively through surveys, they have been relatively easy to obtain and share. Methodologies and best practices were developed in companies and in marketing research organizations. During the 1990s, for example, all of the major marketing research suppliers had units or practices in customer satisfaction, and the American Marketing Association sponsored an annual Customer Satisfaction Congress that often drew close to 1,000 registrants from companies. Second, using these metrics as dependent variables allowed companies to diagnose key attribute drivers that could then be addressed by specific marketing and operational strategies within a company. Third, the measures helped companies track performance over time, benchmark against competitors' offerings, and compare performance across different parts of an organization (e.g., branches, units, territories, countries).

Of all the unobservable metrics, customer satisfaction has been the most widely studied by researchers and used by firms because the construct is generic and can be universally gauged for all products and services (including nonprofit and public services). Even without a precise definition of the term, customer satisfaction is clearly understood by respondents and its meaning is easy to communicate to managers. Other unobservable measures-such as service quality, loyalty, and intentions to purchase-have also had widespread use in companies and been examined extensively in academic research. To a far lesser extent, constructs such as commitment, perceived value, and trust have made their way into company measurement systems and academic research. Other possible measures, such as product quality, have not been measured consistently enough to be linked to behaviors or financial performance in studies. We focus on the metrics of customer satisfaction, service quality, loyalty, and intentions to purchase in this paper because of their prevalence in use and maturity in measurement. For a variety of reasons, we chose to eliminate perceived value, trust, and commitment from this discussion.

Perceived value was excluded because it is the most ambiguous and idiosyncratic customer metric. While it can be defined in a general sense, operationalizing and measuring the construct has proven difficult. Most definitions state that perceived value is the consumer's objective assessment of the utility of a brand 
based on perceptions of what is given up for what is received (e.g., Zeithaml 1988). However, this definition itself is so broad and vague that the construct is virtually impossible to measure with validity, reliability, and consistency. In many academic and company studies, perceived value has been measured with a single item or a small number of items (Bolton and Drew 1991), but these measures leave to the customer the precise meaning of the term. Researchers have developed complex conceptualizations and measures (Sirdeshmukh et al. 2002), but these measures are not used in any consistent manner across studies and within companies.

We also eliminated commitment as a metric in this paper. Commitment is a construct that has been proposed as an alternative to customer satisfaction because it signifies a stronger attachment to a product or company. Moorman et al. $(1992$, p. 316) define commitment as "an enduring desire to maintain a valued relationship." A small number of studies have measured commitment in business-to-business (B2B) contexts (Gruen et al. 2000, Morgan and Hunt 1994), consumer contexts (Verhoef et al. 2002), and in the context of relational ties among channel members (Kim and Frazier 1997, Kumar et al. 1995). Many researchers in marketing have viewed commitment as a unidimensional concept and measured it simply, but others have elaborated dimensions and attributes (Garbarino and Johnson 1999, MacKenzie et al. 1998, Morgan and Hunt 1994). The inconsistent conceptualizations, particularly among components of commitment, have led to myriad ways to measure the concept. Because the research on commitment has rarely been linked to the behavioral or financial variables we emphasize in this paper, we eliminated commitment from our study.

\subsection{Customer Satisfaction}

Customer satisfaction has been defined in many different words, but essentially as the consumer's judgment that a product or service meets or falls short of expectations. Research has typically portrayed the evaluation of customer satisfaction as disconfirmation of expectations (see Oliver 1997 or Yi 1990 for a full review). This view holds that a consumer compares what is received with a preconsumption standard or expectation.

One of the pivotal definitional issues in the literature is whether satisfaction is best conceived as a transaction-based evaluation or as an overall, cumulative evaluation similar to attitude. Traditionally, satisfaction was viewed as transaction specific, an immediate postpurchase evaluative judgment or affective reaction (Oliver 1993). Reflecting the more global perspective, studies such as Anderson and colleagues (1994) consider satisfaction to be an "overall evaluation based on the total purchase and consumption experience with a good or service over time" (p. 54).
Both in practice and in academic research, customer satisfaction has been measured at the transaction level (as in trailer or event-triggered surveys) and at the overall level (as in the American Customer Satisfaction Index). In early studies, academics often focused on measuring confirmation or disconfirmation, and expectations, and the nature and type of expectations varied considerably from predictive expectations (Oliver 1997, Tse and Wilton 1988), to desires and experience-based norms (Cadotte et al. 1987). Applied marketing research tends to measure satisfaction at the transaction level but more recently as an overall evaluation, a cumulative construct that is developed over all the experiences a customer has with a firm.

\subsection{Service Quality}

Perceived service quality is the degree and direction of discrepancy between customers' service perceptions and expectations (Sasser et al. 1978, Zeithaml and Parasuraman 2004). While multiple interpretations of expectations have emerged in service quality research as they have in customer satisfaction research, the notion that service quality is a comparative process is one of the basic building blocks in the field.

The dominant measurement approach for quantitative assessment of service quality is SERVQUAL, a multiple-item measure first developed in the 1980s, then tested and refined throughout the 1990s (see a review in Zeithaml and Parasuraman 2004). Researchers first operationalized the service quality gap as the difference between two scores-customer expectations and perceptions of actual service performance for the perceptual attributes that respondents indicated were pivotal. Through this early research five dimensions of service quality were derived as factors: reliability, responsiveness, assurance, empathy, and tangibles (Zeithaml and Parasuraman 2004). Refinement and assessment of SERVQUAL over two decades indicate that it is a robust measure of perceived service quality. However, concerns about SERVQUAL have been raised and debated, including the interpretation of and need to measure expectations, the appropriateness of measuring service quality using difference scores, and the generalizability of the five dimensions across all service contexts.

\subsection{Loyalty and Intentions to Purchase}

Behaviorally, consumers can be defined as loyal if they continue to buy the same product over some period of time. Jacoby and Chestnut (1978), however, took exception to this simple definition and were the first researchers to view loyalty psychologically rather than behaviorally. They recognized that behavioral loyalty could be spurious because it could be based on convenience and switching costs, or misleading 
if consumers were multibrand loyal. In a representative definition that combines both the behavioral and attitudinal perspectives, Oliver (1997, p. 392) defines loyalty comprehensively as

a deeply held commitment to rebuy or repatronize a preferred product/service consistently in the future, thereby causing repetitive same-brand or same brandset purchasing, despite situational influences and marketing efforts having the potential to cause switching behavior.

Consumer loyalty is indicated by an intention to perform a diverse set of behaviors that signal a motivation to maintain a relationship with the focal firm, including allocating a higher share of the category wallet to the specific service provider, engaging in positive word of mouth, and repeat purchasing (Zeithaml et al. 1996).

Loyalty has been measured behaviorally as repeat purchase frequency or relative volume of purchasing (Tellis 1988); and attitudinally as repurchase intentions (e.g., Reynolds and Arnold 2000), intention to recommend to others (e.g., Mattila 2001), and likelihood of switching and likelihood of buying more (e.g., Selnes and Gonhaug 2000). Zeithaml et al. (1996) combine these different aspects of loyalty and develop a behavioral-intentions battery with four factorsloyalty, propensity to switch, willingness to pay more, and external response to service problemscomprising 14 specific behavioral intentions likely to result from perceived service quality.

In a departure from the rigor of academic research, some scholars and practitioners claim that complex measurements are unnecessary to capture loyalty. Notably, Reichheld (2003) claims that the only number a company needs is one that reflects customers' intention to recommend the firm to others. Reichheld suggests using a net promoter score, defined as the percentage of respondents answering 9 and 10 on a 10-point willingness-to-recommend scale, minus the percentage of respondents answering 0 through 6 . Reichheld argues that companies commonly get net promoter scores that range from $10 \%$ to $16 \%$, and that the best companies get scores between $75 \%$ and $80 \%$. Because of its simplicity and ease of measurement, the index has gained popularity with many companies. General Electric (GE) CEO Jeffrey Immelt encourages his executives to use net promoter scores in all of GE's divisions. The Wall Street Journal, Symantec, and Intuit are other proponents of the net promoter score.

\section{Observable or Behavioral Customer Metrics}

The implicit assumption in using unobservable customer metrics is that they anticipate or predict observable behavior such as retention or increased consumption. In the 1990s, companies began to question whether the relationship between unobservable measures such as customer satisfaction and observable behavior such as purchasing was sufficiently strong to justify its use as the primary unobservable predictor. Additionally, as database management and customer relationship management have evolved, researchers and companies find that they can bypass unobservable metrics and directly link a firm's actions to customers' observable behavior and the firm's financial performance.

In this section, we discuss behavioral and observable outcome metrics. These metrics include customer decisions of what, when, how much, and where to purchase products or services. A vast literature on choice models attempts to elucidate the impact of marketing variables on such consumer decisions (e.g., Guadagni and Little 1983, Gupta 1988). The equivalent decisions from a firm's perspective are which customers to acquire, how to retain them, and how to cross-sell different products and services to them. Research in customer relationship management (CRM) uses this terminology (e.g., Kamakura et al. 2005). Even though the terminology used by these two streams is different, they are effectively capturing similar aspects of consumer purchase behavior. For example, models of cross-category purchase (e.g., Manchanda et al. 1999, Iyengar et al. 2003) can also be used for the purpose of cross-selling. We will adopt the terminology and the metrics used in CRM in this paper because they have direct implications for firms' financial performance. Specifically, we will focus on customer acquisition, retention, and crossselling, which in turn determine customer lifetime value (CLV) and customer equity (CE).

\subsection{Customer Acquisition}

Customer acquisition refers to the first-time purchase by new or lapsed customers. The basic model for customer acquisition is a logit or a probit. Specifically, customer $j$ buys at time $t$ (i.e., $Z_{j t}=1$ ) as follows:

$$
\begin{gathered}
Z_{j t}^{*}=\boldsymbol{\alpha}_{j} \mathbf{X}_{j t}+\varepsilon_{j t}, \\
Z_{j t}=1 \quad \text { if } Z_{j t}^{*}>0, \\
Z_{j t}=0 \quad \text { if } Z_{j t}^{*} \leq 0,
\end{gathered}
$$

where $\mathbf{X}_{j t}$ are the covariates and $\alpha_{j}$ are consumerspecific response parameters. Depending on the assumption of the error term, one can obtain a logit or a probit model (Thomas 2001, Lewis 2005b). Some researchers (e.g., Kim et al. 1995, Gupta et al. 2004) have followed the diffusion modeling tradition to forecast the number of new customers. For example, Gupta et al. (2004) suggest the following model for forecasting the number of new customers at time $t$ :

$$
n_{t}=\frac{\alpha \gamma \exp (-\beta-\gamma t)}{[1+\exp (-\beta-\gamma t)]^{2}}
$$


where $\alpha, \beta$, and $\gamma$ are the parameters of the customer growth curve. As in the diffusion literature, marketing mix covariates can also be included in this model.

Most studies on customer acquisition examine the short- and long-run impacts of marketing variables on the construct. As an example, Thomas et al. (2004) find that while low price increase probability of acquisition, it reduces relationship duration. Therefore, customers who may be inclined to restart a relationship may not be the best customers to retain. Similarly, Lewis (2003) shows how promotions that enhance customer acquisition may be detrimental in the long run. In contrast, Anderson and Simester (2004) find that deep price discounts have a positive impact on the long-run profitability of first-time buyers, but have a negative long-term impact on established customers.

\subsection{Customer Retention}

Customer retention is the probability of a customer being "alive," or repeat buying from a firm. In contractual settings (e.g., cellular phones), firms clearly know when customers terminate relationships. However, in noncontractual settings (e.g., buying books from Amazon) firms must infer whether a customer is still active.

Two broad classes of retention models exist- "lost for good" and "always a share" (Dwyer 1997, Jain and Singh 2002). The lost for good class considers customer defection as permanent, while the always a share class considers customers switching to competitors as transient. The former class typically predicts the probability of customer defection using hazard models, which fall into two broad groups-accelerated failure time (AFT) or proportional hazard (PH) models. The AFT models have the following form for customer $j$ (Kalbfleisch and Prentice 1980):

$$
\ln \left(y_{j}\right)=\boldsymbol{\beta}_{j} \mathbf{W}_{j}+\sigma \mu_{j},
$$

where $y$ is the purchase duration and $\mathbf{W}$ are the covariates. Different specifications of $\sigma$ and $\mu$ lead to different models such as Weibull or generalized gamma (Allenby et al. 1999, Venkatesan and Kumar 2004). For example, if $\sigma=1$ and $\mu$ has an extreme value distribution, then we get an exponential duration model with constant hazard rate.

PH models are another group of commonly used duration models. These models specify the hazard rate $(\lambda)$ as a function of baseline hazard rate $\left(\lambda_{0}\right)$ and covariates $(\mathbf{W})$ :

$$
\lambda(t ; W)=\lambda_{0}(t) \exp (\boldsymbol{\beta W}) .
$$

Different specifications for the baseline hazard rate provide different duration models such as exponential, Weibull, or Gompertz. This approach has been used by Bolton (1998) and Gonul et al. (2000). Other researchers have used semiparametric models where the baseline hazard is discretized for each time interval (Manchanda et al. 2005).

Schmittlein et al. (1987) and Schmittlein and Peterson (1994) propose a negative binomial distribution (NBD) or Pareto model for assessing the probability that a customer is still alive. This model has been used by Reinartz and Kumar (2000) and modified recently by Fader et al. (2005).

Instead of modeling duration of relationship, one can model whether or not a customer is likely to defect in a prespecified time period using a form of discrete-time hazard model. Examples of these are logistic or probit models. Neslin et al. (2006) describe such models that were submitted by several academics and practitioners as part of a churn tournament. Models emanating from machine learning, such as bagging and boosting, have also been recently used for modeling customer churn (Lemmens and Croux 2005).

The always a share retention models view customers switching to competitors as transient. This category typically uses migration or Markov models to estimate transition probabilities of customers being in a certain state. Bitran and Mondschein (1996), Gonul and Shi (1998), and Pfeifer and Carraway (2000) define these states based on recency frequency and monetary or RFM value measures, while Rust et al. (2004) use brands as states and estimated transition probabilities using a logit model. Iyengar (2004) defines wireless phone plans and customer defection as states, thereby using a structural model to obtain transition probabilities. Simester et al. (2006) use a binary tree approach to define the state space, and estimate the transition probabilities using a nonparametric approach. Most of these studies use dynamic programming to arrive at the optimal marketing programs that maximize firm profits. While the idea of using dynamic programming to determine marketing policy is not new, the availability of large-scale data and the computing power has generated a renewed interest in this area. It is interesting to note that the dynamic programming approach allows the managerial flexibility by considering the value of options to base marketing policy on customer states.

As mentioned earlier, retention models are typically categorized into two groups-lost for good or always a share. Recently, some researchers have argued that customers should be treated as a renewable resource (Drèze and Bonfrer 2005). Thomas et al. (2004) explicitly build a model for recapturing lost customers.

Studies have suggested models that link customer acquisition and retention. For example, Hansotia and Wang (1997) indirectly link acquisition and retention using a logit model for acquisition and a right-censored 
Tobit model for CLV. More recently, researchers have explicitly linked acquisition and retention. Thomas (2001) and Thomas et al. (2004) use Equation (1) for customer acquisition, and a variant of Equation (3) for customer retention. Retention is linked to acquisition through the error correlation between the two models.

Firms use a variety of programs to enhance customer retention. Loyalty programs are perhaps one of the most commonly used marketing instruments. Since the introduction of frequent flier programs by American Airlines in the 1980s, loyalty programs (LPs) have become ubiquitous in almost every industry. The interest in LPs has increased over time as more and more companies use them for developing relationships, stimulating product or service usage, and retaining customers. In spite of the pervasiveness of LPs, their effectiveness is far from clear. Some studies find that they increase customer retention (Bolton et al. 2000); others find no impact on retention but do find improvement in share of wallet (Sharp and Sharp 1997); and yet others find almost no difference in the behavior of LP members and nonmembers (Dowling and Uncles 1997). Shugan (2005) suggests that LPs are shams because they produce liabilities rather than assets. Even if LPs work, which customers do they work for the best? Conventional wisdom suggests that LPs should be designed to reward a firm's best customers. However, a recent study by Lal and Bell (2003) finds that in the context of grocery stores, LPs have the biggest impact on a store's worst (or low-spending) customers.

One of the challenges in studying the effectiveness of LPs is the issue of endogeneity-customers who sign up for LPs are likely to be different (e.g., heavier buyers) than those who don't sign up for these programs. Therefore, a simple comparison of buying behavior of LP members and nonmembers may overestimate the effectiveness of these programs. Leenheer et al. (2003) examine seven supermarkets' LPs and account this endogeneity issue through instrumental variables. They find that LPs generally increase shareof-wallet. However, four of the seven programs were ineffective.

\subsection{Cross-Selling}

As cost of customer acquisition increases, firms attempt to maximize returns from existing customers. Cross-selling-attempting to sell related products to current customers-involves decisions such as assessing which products to cross-sell, to whom, and at what time. Cross-selling research also includes the choice of appropriate marketing instruments (e.g., contact strategy or pricing).

In many product categories, customers acquire products in some natural sequence. For example, in financial services, customers may start with a checking or savings account and over time buy products that are more complex such as loans and stocks. Kamakura et al. (1991) argue that customers are likely to buy products when they reach a financial maturity commensurate with the complexity of the product. They model this by positioning products and consumers along a common latent difficulty and ability dimension. Specifically, the probability that consumer $j$ would buy product $k$ is given by

$$
P_{j k}=\left[1+\exp \left\{\alpha_{k}\left(\beta_{k}-O_{j}\right)\right\}\right]^{-1},
$$

where $O_{j}$ is the position of consumer $j$ and $\beta_{k}$ is the position of product $k$ along the latent dimension.

$\mathrm{Li}$ and colleagues (2005) use a similar conceptualization for cross-selling sequentially ordered financial products. Instead of a logistic model, they use a multivariate probit model. This model was earlier posited by Manchanda et al. (1999) to model consumer purchases of multiple product categories. Here,

$$
\begin{gathered}
\mathbf{u}_{j t}=\mathbf{X}_{j t} \boldsymbol{\beta}_{j}+\boldsymbol{\varepsilon}_{j t}, \\
\boldsymbol{\varepsilon}_{j t} \sim \operatorname{MVN}(\mathbf{0}, \Sigma),
\end{gathered}
$$

where $\mathbf{u}_{j t}$ is the vector of utilities for consumer $j$ at time $t$ for multiple products, $\mathbf{X}$ are covariates, and $\boldsymbol{\varepsilon}$ are the errors that are correlated across products. $\mathrm{Li}$ et al. (2005) use latent dimension of Kamakura et al. (1991) and ownership of previous products as two of the covariates in Equation (6). Verhoef et al. (2001) use an ordered probit to model consumers' cross-buying. Knott et al. (2002) use logit, discriminant analysis, and neural network models to predict the next product to buy.

The models discussed to this point focus only on which product a customer is most likely to buy next. Knott et al. (2002) augment their choice model with a hazard model to predict the timing of this purchase. Kamakura et al. (2004) use a multivariate split hazard model to find physicians' propensity to ever prescribe a drug, as well as the timing of the adoption of that drug. The likelihood for physician $j$ to prescribe drug $k$ is

$$
L_{j}=\prod_{k \in C_{j}} \theta_{j k} f\left(t_{j k}\right) \prod_{k \notin C_{j}}\left[\theta_{j k} S\left(t_{j k}\right)+\left(1-\theta_{j k}\right)\right],
$$

where $\theta_{j k}$ is the probability that physician $j$ will ever prescribe drug $k$ (this allows for the possibility that some physicians would never adopt a drug, and hence the name split hazard), $C_{j}$ is the set of drugs adopted by physician $j, f$ is the density function, and $S$ is the survival function for adoption time.

In principle, many of these models are similar to the choice and incidence models used by researchers many years ago to model consumer purchases in scanner panel data (e.g., Gupta 1988). Current researchers have simply augmented these models by including current ownership of Product A as a covariate to predict purchase behavior of Product B. 


\subsection{Customer Lifetime Value}

Customer acquisition, retention, and cross-selling determine the long-run profitability or lifetime value of a customer. $C L V$ is defined as the present value of all future profits obtained from a customer over the life of his relationship with a firm. CLV is similar to the discounted cash flow approach used in finance except for two key differences. First, CLV is defined at an individual customer or segment level, recognizing that some customers are more important and profitable than others. Second, CLV explicitly incorporates the possibility of a customer defecting to competitors in the future.

CLV for a customer (for simplicity we are omitting consumer subscript) has been modeled in two ways. The first approach estimates a customer's expected life $T^{*}$ (based on a retention model) and evaluates the net present value (NPV) over this time horizon (Reinartz and Kumar 2000, Thomas 2001). Specifically,

$$
\mathrm{CLV}=\sum_{t=0}^{T^{*}} \frac{\left(p_{t}-c_{t}\right)}{(1+i)^{t}}-\mathrm{AC}
$$

where

$$
\begin{aligned}
p_{t} & =\text { price paid by a consumer at time } t, \\
c_{t} & =\text { direct cost of servicing the customer at time } t, \\
i & =\text { discount rate or cost of capital for the firm, } \\
T^{*} & =\text { expected lifetime of a customer, } \\
\mathrm{AC} & =\text { acquisition cost. }
\end{aligned}
$$

Two other modifications are possible in this approach. First, rather than a discrete time frame, the model can be constructed for continuous time. Second, instead of estimating CLV up to time $T^{*}$, an infinite time horizon can be used (Dreze and Bonfrer 2005). Note, crossselling and up-selling are implicitly built in this model since these will change the profit $(p-c)$ generated by a customer at any point in time.

Alternatively, the probability of retention is directly included in the CLV equation, as follows (Gupta et al. 2004, Reinartz and Kumar 2003),

$$
\mathrm{CLV}=\sum_{t=0}^{T} \frac{\left(p_{t}-c_{t}\right) r_{t}}{(1+i)^{t}}-\mathrm{AC},
$$

where $r_{t}=$ probability of customer repeat buying or being alive at time $t, T=$ time horizon for estimating CLV.

Gupta and Lehmann (2005) show that using Equation (8) generally overestimates CLV, sometimes substantially. This results from the implicit assumption in Equation (8) that even if a customer's retention probability is, say, 0.8 , she is providing profits for the next five years with certainty.

Researchers commonly build separate models for future contribution margin $\left(p_{t}-c_{t}\right)$ and probability of repeat buying or being alive in the future $\left(r_{t}\right)$, then combine them to estimate CLV. Most studies either use average contribution margin based on past purchase data (Reinartz and Kumar 2000, Gupta et al. 2004) or a Tobit model to predict it (Lewis 2003). Gupta and Lehmann (2003, 2005) argue that under a variety of conditions it may be appropriate to consider a constant margin $(m=p-c)$ and constant retention rate $(r)$ per time period so that retention probability in period $t$ is simply $r^{t}$. Using an infinite time horizon, CLV greatly simplifies to the following expression:

$$
\mathrm{CLV}=\sum_{t=0}^{\infty} \frac{(p-c) r^{t}}{(1+i)^{t}}=m \frac{r}{(1+i-r)}
$$

In other words, CLV simply becomes margin $(m)$ times a margin multiple $(r /(1+i-r))$. When retention rate is $90 \%$ and discount rate is $12 \%$, the margin multiple is about four. Gupta and Lehmann (2005) show how Equation (10) can be modified when margin and retention rates are not constant.

\subsection{Customer Equity}

CLV is the long-run profitability of an individual customer. It is useful in identifying which customers to acquire, how much to spend on them, and how to customize marketing and product offerings to them. While this micromarketing is useful from an operational perspective, it must be aggregated at a higher level to be a useful metric for senior managers. For this purpose, many researchers focus on customer equity (CE), which is defined as the lifetime value of current and future customers (Blattberg et al. 2001, Rust et al. 2004, Gupta and Lehmann 2005).

Recently, some researchers have demonstrated a link between CE and firms' market value (discussed in \$6). Others have shown that decisions based on $\mathrm{CE}$ can be qualitatively different from the decisions that focus on share and sales (Yoo and Hanssens 2004).

\section{Link Between Unobservable Metrics and Financial Performance}

Do customer satisfaction and other perceptual metrics lead to improved financial performance? Most recent research has focused on exploring or establishing a link between satisfaction and financial impact. Researchers have used different metrics for financial performance: profit, stock price, Tobin's $q$ (ratio of market value of a firm to the replacement cost of its tangible assets) (Gruca and Rego 2005, Anderson et al. 2004), return on assets (ROA; Hallowell 1996), return on investment (ROI; Anderson and Mittal 2000, Anderson et al. 1994), abnormal earnings (Nayyar 1995), and cash flows (Rust et al. 2004). Based on a 


\begin{tabular}{|c|c|c|}
\hline Study & Data & Results \\
\hline Anderson et al. (2004) & $\begin{array}{l}200 \text { Fortune } 500 \text { firms in } 40 \text { industries during 1994-97 } \\
\text { with ACSI, } 1-100 \text { scale }\end{array}$ & $\begin{array}{l}1 \% \text { change in ACSI } \rightarrow 1.016 \% \text { change in Tobin's } q \text { or } \\
\$ 275 \text { million in firm value. }\end{array}$ \\
\hline Ittner and Larcker (1998) & 140 firms and ACSI index & $\begin{array}{l}\text { One unit increase in ACSI } \rightarrow \$ 240 \text { million increase in } \\
\text { market value. }\end{array}$ \\
\hline Gruca and Rego (2005) & $\begin{array}{l}\text { ACSI and Compustat data from 1994-2002 for } 105 \text { firms } \\
\text { in } 23 \text { industries }\end{array}$ & $\begin{array}{l}\text { One point increase in ACSI } \rightarrow \$ 55 \text { million increase in cash } \\
\text { flow in the next year and } 4 \% \text { reduction in variability. }\end{array}$ \\
\hline Anderson and Mittal (2000) & 125 firms and SCSB & $\begin{array}{l}1 \% \text { increase in satisfaction } \rightarrow 2.37 \% \text { increase in } \mathrm{ROI} \text {. } \\
1 \% \text { drop in satisfaction } \rightarrow 5.08 \% \text { drop in } \mathrm{ROI} \text {. }\end{array}$ \\
\hline Anderson et al. (1997) & Swedish data for 1989-92 & Satisfaction elasticity for $\mathrm{ROI}=0.14-0.27$ \\
\hline Anderson et al. (1994) & Swedish data on 77 firms & $\begin{array}{l}\text { One point increase in SCSB } \rightarrow 11 \% \text { of current ROI or } \\
\$ 94 \text { million. } \\
\text { Short-run elasticity of ROI with respect to quality }=0.196 \text {. }\end{array}$ \\
\hline Hallowell (1996) & $\begin{array}{l}1 \text { retail bank, } 59 \text { divisions } \\
12,000 \text { retail banking customers satisfaction measured } \\
\text { on } 1-7 \text { scale }\end{array}$ & $\begin{array}{l}\text { One point change in satisfaction } \rightarrow 0.59 \% \text { point change } \\
\text { in } R O A \text {. }\end{array}$ \\
\hline Nayyar (1995) & 106 firms from 68 industries for $1981-91$ & $\begin{array}{l}\text { Increase in customer service } \rightarrow 0.46 \% \text { average CAR. } \\
\text { Decrease in customer service } \rightarrow-0.22 \% \text { CAR. }\end{array}$ \\
\hline Rucci et al. (1998) & Sears 1994-95 & $\begin{array}{l}4 \% \text { increase in satisfaction } \rightarrow \$ 200 \text { million in additional } \\
\text { revenue or } \$ 250 \text { million in market cap. }\end{array}$ \\
\hline Nelson et al. (1992) & 51 general hospitals, each with a sample of 300 patients & $\begin{array}{l}\text { Service quality explains } 17 \%-27 \% \text { of variation in financial } \\
\text { performance of hospitals. }\end{array}$ \\
\hline Rust et al. (1995) & $\begin{array}{l}7,882 \text { responses over one year from a national hotel chain } \\
\text { customers }\end{array}$ & $44.6 \%$ projected return on quality. \\
\hline Aaker and Jacobson (1994) & $\begin{array}{l}34 \text { firms and 1,000-2,000 customer surveys over } \\
\text { four years }\end{array}$ & Quality perceptions $\rightarrow$ stock returns. \\
\hline
\end{tabular}

review of more than two decades of research, we offer the following empirical generalizations. ${ }^{2}$

GeNerALIZATION 1. Improvement in customer satisfaction has a significant and positive impact on firms' financial performance.

Many studies have shown a strong link between customer satisfaction and firm profitability (Table 1). Using 200 of the Fortune 500 firms across 40 industries, Anderson et al. (2004) show that while market share has no impact on shareholder value, a $1 \%$ change in ACSI (as measured by the American Customer Satisfaction Index on a $0-100$ scale) is associated with a $1.016 \%$ change in shareholder value as measured by Tobin's $q$. This implies that $1 \%$ improvement in satisfaction for these firms will lead to an increase in a firm's value of approximately $\$ 275$ million. Ittner and Larcker (1998) also use ACSI and financial data on 140 firms and find remarkably similar results. Specifically, they demonstrate that a onepoint increase in ACSI leads to a $\$ 240$ million increase in market value of a firm. Using similar data, Gruca and Rego (2005) find that a one-point increase in ACSI results in an increase of $\$ 55$ million in a firm's

\footnotetext{
${ }^{2}$ There is a vast literature on each topic. Given the space constraints, we are able to highlight only a few main studies in each area.
}

net operational cash flow the following year and a decrease of $4 \%$ in cash flow variability.

Anderson and Mittal (2000) examine the data from 125 Swedish firms using the Swedish Customer Satisfaction Barometer (SCSB) and find that a $1 \%$ increase in satisfaction leads to a $2.37 \%$ increase in ROI. With the SCSB data for 1989-92, Anderson and colleagues (1997) find that satisfaction elasticity for ROI ranges from 0.14 to 0.27 . The Swedish data lead Anderson et al. (1994) to conclude that a one-point annual increase in SCSB for five years is worth about $\$ 94$ million or $11.4 \%$ of current ROI. Using data from 12,000 retail banking customers from 59 divisions of a retail bank, Hallowell (1996) supports results from SCSB data by showing that a one-point improvement in satisfaction (on a $1-7$ scale) increases ROA by $0.59 \%$.

With data from 106 firms in 68 industries during the period 1981-91, Nayyar (1995) finds that news reports about increases in customer service lead to average cumulative abnormal earnings (CAR) of about $0.46 \%$, or $\$ 17$ million in market value. Ittner and Larcker (1998) also find that announcement of ACSI improvement leads to an increase in abnormal returns approximating $1 \%$ in a 10 -day period.

Rucci et al. (1998), describing the transformation at Sears during the period 1994-95, develop a model to relate changes in employee attitude, customer satisfaction, and revenue growth. Results indicate that 
a five-point improvement in employee attitude leads to a 1.3 point improvement in customer satisfaction, which in turn leads to a $0.5 \%$ improvement in revenue growth. They further estimate that a $4 \%$ improvement in customer satisfaction translates to more than $\$ 200$ million in additional 12-month revenues. These extra revenues would increase Sears's market capitalization by nearly $\$ 250$ million.

Some studies explicitly consider the impact of service quality on financial performance, while others subsume service quality as a driver of customer satisfaction and therefore focus on the impact of satisfaction on financial performance. With profit impact of movicet strategies (PIMS) data, Buzzell and Gale (1987) find that the short-run elasticity of ROI of quality is 0.25. Anderson et al. (1994) report this elasticity at about 0.2 from the Swedish data. Nelson et al. (1992), with data from 51 hospitals, find that selected dimensions of service quality explain $17 \%-$ $27 \%$ of the variation in financial measures such as hospital earnings, net revenue, and ROA. Using data from almost 8,000 customers of a national hotel chain, Rust et al. (1995) find that ROI in service quality (e.g., cleanliness) is almost 45\%. Aaker and Jacobson (1994), using data from 34 firms and more than 1,000 customer surveys, conclude that quality perceptions positively influence stock returns even after controlling for accounting measures.

Collectively, these studies show a strong and positive impact of customer satisfaction on firm performance. They further provide a rough benchmark about the effect size. For example, Anderson et al. (2004) and Ittner and Larcker (1998) show that a $1 \%$ change in ACSI can lead to a \$240-\$275 million improvement in firm value. In sum, these results provide a strong guideline to firms about how much they should spend on improving customer satisfaction.

Generalization 2. The link between satisfaction and profitability is asymmetric and nonlinear.

While there are fewer studies in this area than discussed in Generalization 1 (G1), their collective conclusion provides strong support for Generalization 2 (G2). Anderson and Mittal (2000) find that a $1 \%$ increase in satisfaction leads to a $2.37 \%$ increase in ROI, while a $1 \%$ drop in satisfaction reduces ROI by $5.08 \%$. Nayyar (1995) finds that positive news about customer service leads to an increase in CAR of about $0.46 \%$, while reports of reductions in customer service are met with declines in CAR of about half, or $0.22 \%$. Anderson and Mittal (2000) document several studies that find both asymmetric and nonlinear effects across the service profit chain (similar to Figure 1). Roy (1999) shows that using a linear approach underestimates the impact of completely satisfying physicians by $31 \%$, which would represent an underestimation of revenue by $\$ 150$ million.

Although several studies have established the asymmetric and nonlinear nature of the link between satisfaction and profitability, the exact form of this nonlinearity needs further examination. For example, Anderson and Mittal (2000) find that a drop in satisfaction produces twice the impact on ROI than an increase in satisfaction produces. In contrast, Nayyar (1995) finds negative news of customer service has only half the impact on CAR than the positive news has. Based on prior research that shows a strong impact of negative word of mouth, we speculate that a decrease in satisfaction is likely to have a much stronger impact on ROI than an increase in satisfaction.

Generalization 3. The strength of the satisfactionprofitability link varies across industries as well as across firms within an industry.

In G1, we showed the impact of satisfaction on firm profitability on average, but the strength of this relationship is not consistent across industries. Ittner and Larcker (1998) confirm this by showing that the value relevance of customer satisfaction varies across industries. Using ACSI on 140 firms from five different industries, they find that ACSI has a positive but insignificant impact on market value of durable and nondurable manufacturing firms, but a positive and significant impact on the market value of transportation, utility, and communication firms. The effect is strongly negative for retailers. Anderson et al. (1997) find that trade-offs between customer satisfaction and productivity (e.g., labor productivity) are more likely for services than for goods. Specifically, a simultaneous $1 \%$ increase in customer satisfaction and in productivity is likely to increase ROI by $0.365 \%$ for goods, but only $0.22 \%$ for services.

Anderson et al. (2004) also find significant differences in the satisfaction-profitability link across industries. While a $1 \%$ change in satisfaction has an average impact of $1.016 \%$ on shareholder value (Tobin's q), the impact ranges from $2.8 \%$ for department stores to $-0.3 \%$ for discount stores. They further demonstrate that only $14.5 \%$ of the variance in association between ACSI and Tobin's $q$ is due to industry differences, with $85.5 \%$ due to differences across firms within the same industry. Gruca and Rego (2005) find that industry characteristics explain $35 \%$ of the variance in cash flow growth and $54 \%$ of the variance in cash flow variability. They also found that the influence of customer satisfaction on cash-flow growth is greatest for low-involvement, routinized, and frequently purchased products (e.g., beer and fast food). Although these studies find significant differences across industries and firms, two questions remain. First, do some 
industries or firms systematically show a stronger link between satisfaction and profitability? Ittner and Larcker (1998) find a negative link in the retail industry, while Anderson et al. (2004) show the strongest positive link in the same industry. Second, why is this link stronger for some industries or firms than for others?

We make the following conjectures about these questions. First, a satisfaction-profit link is likely to show greater variations among firms within the same industry rather than across industries. This conjecture is partly supported by Anderson et al. (2004), who show that only $14.5 \%$ of the variation in the association between ACSI and Tobin's $q$ is explained by industry differences. Second, satisfaction is likely to have a larger impact in service industries where customers are highly involved (e.g., financial services). This is due to the fact that unlike the manufacturing firms where product quality is determined in the factory, the quality of a service firm is determined by the frontline employees. The latter is likely to have far more variation than the former. Third, within an industry, variations in this link across firms are likely to depend on execution and efficiency. This conjecture is partly supported by Mittal et al. (2005), who use a longitudinal data set of 77 firms from the United States and find that the relationship between customer satisfaction and long-term financial performance is positive and relatively stronger for firms that successfully achieve a dual emphasis, i.e., that achieve customer satisfaction and efficiency simultaneously. For a typical firm in their database with a market value of $\$ 46$ billion, they find that a one-point increase in ACSI is worth $\$ 1.613$ billion in market value to a high-efficiency firm, and only \$298 million for a lowefficiency firm.

\section{Link Between Unobservable and Observable Metrics}

In a recent paper, Kamakura et al. (2002) show that superior satisfaction alone is not an unconditional guarantee of profitability. Based on their analysis of 500 branches of a national bank in Brazil, they further argue that managers should not only be efficient in achieving superior customer satisfaction, but should also be efficient in translating these attitudes and intentions into relevant behaviors. Similarly, Reichheld (1996) cautions against the exclusive use of satisfaction without establishing its link with retention and profits. He argues that, in the automobile industry, dealers are gaming satisfaction measures without necessarily improving customer value. Based on research conducted by Bain \& Company, he finds that in many businesses $60 \%-80 \%$ of defected customers said, when surveyed just prior to defecting, that they were satisfied or very satisfied. This concern argues even more in favor of establishing a link between satisfaction and retention.

Despite these and other calls for research linking observable and unobservable metrics, most marketing studies that examine the association between customer satisfaction and purchase measure of purchase intent rather than actual behavior (e.g., Anderson and Sullivan 1993, Rust et al. 1995) using surveys. Although these studies show a strong link between satisfaction and purchase intent, they do not establish the relationship with actual behavior. Using a survey to measure both satisfaction and purchase intent creates strong method bias. For example, Mazursky and Geva (1989) find that satisfaction and intentions are highly correlated when measured in the same survey (time $t_{1}$ ), but that the same subjects' satisfaction at $t_{1}$ had no correlation with their intentions after a twoweek interval $\left(t_{2}\right)$. In a longitudinal study, Mittal et al. (1999) find that the relationship between satisfaction and behavioral intentions can increase or decrease over time. They contend that estimates based on a single cross-section alone can be misleading, and that the type of behavior intent (e.g., purchase versus recommend) can affect the strength of the relationship.

Because the relationship between customer satisfaction and purchase intent may be attributed to common-methods variance, the relationship may appear stronger than it is (Fishbein and Ajzen 1975, Mittal and Kamakura 2001). To avoid this bias, Mittal and Kamakura (2001) study the relationship between satisfaction and actual repurchase behavior, believing that the satisfaction threshold needed for a subject to indicate purchase intent may differ from the threshold needed to actually purchase. They find that consumers that vary on demographic characteristics such as age and education have different thresholds of satisfaction for repurchase. Repurchase rates with customer groups at the same levels of satisfaction vary systematically with these characteristics, with one customer group showing no correlation at all $(r=0)$ between customer satisfaction and repurchase. Mittal and Kamakura (2001) also find that the functional forms linking satisfaction to intentions and behavior differ, with repurchase intent exhibiting decreasing returns and repurchase behavior exhibiting monotonically increasing returns.

In the three generalizations offered below, we focus largely on studies that show a relationship between unobservable metrics (e.g., satisfaction) and observable actual behavior (e.g., retention or repurchase rather than repurchase intentions).

Generalization 4. There is a strong positive relationship between customer satisfaction and customer retention. However, the relationship between other unobservable and observable metrics is not well established. 


\begin{tabular}{|c|c|c|}
\hline Study & Data & Results \\
\hline Rust and Zahorik (1993) & $\begin{array}{l}100 \text { retail bank customers, of which } 21 \text { had switched } \\
\text { banks }\end{array}$ & $\begin{array}{l}\text { Increase in satisfaction from } 4.2 \text { to } 4.7 \\
\quad \rightarrow \text { increase in annual retention rate from } 95.9 \% \text { to } 96.5 \% \text {. }\end{array}$ \\
\hline Ittner and Larcker (1998) & $\begin{array}{l}2,491 \text { telecommunication customers } \\
73 \text { retail bank branches }\end{array}$ & $\begin{array}{l}\text { 10-point increase in satisfaction ( } 0-100 \text { scale) } \\
\rightarrow 2 \% \text { increase in retention and } \$ 195 \text { increase in revenue per } \\
\text { customer. } \\
\text { Satisfaction positively associated with revenues and number of } \\
\text { customer. }\end{array}$ \\
\hline Bolton (1998) & $\begin{array}{l}650 \text { cellular phone customer tracked over } 22 \text { months } \\
(1991-1993)\end{array}$ & Satisfaction positively related to duration of relationship. \\
\hline Hallowell (1996) & 59 divisions, 12,000 customers of a retail bank & Satisfaction positively related to retention and length of tenure. \\
\hline Loveman (1998) & 450 bank branches and 45,000 customers & $\begin{array}{l}\text { Satisfaction positively related to retention, number of services } \\
\text { used, and share-of-wallet. Biggest impact on cross-sell. }\end{array}$ \\
\hline Verhoef et al. (2001) & $\begin{array}{l}2,018 \text { insurance customers surveyed twice over one-year } \\
\text { period }\end{array}$ & No main effect of satisfaction on cross-buying. \\
\hline Verhoef et al. (2002) & 1,986 insurance customers & $\begin{array}{l}\text { Trust, affective commitment, and satisfaction } \rightarrow \text { referrals; } \\
\text { affective commitment } \rightarrow \text { no. of services purchased. }\end{array}$ \\
\hline Jamieson and Bass (1989) & $\begin{array}{l}900 \text { consumers surveyed over three waves for five } \\
\text { durables and five nondurable products }\end{array}$ & $\begin{array}{l}\text { Only } 10 \% \text { (durables) and } 36 \% \text { (nondurable) of consumers who } \\
\text { indicated that they definitely will or probably will buy, then } \\
\text { actually bought the product. }\end{array}$ \\
\hline Kamakura et al. (2002) & $\begin{array}{l}5,055 \text { customers from } 500 \text { branches of a national bank } \\
\text { in Brazil }\end{array}$ & $\begin{array}{l}\text { Intent to recommend } \rightarrow \text { share-of-wallet, duration of relationship, } \\
\text { and transaction per month. }\end{array}$ \\
\hline Mittal and Kamakura (2001) & 100,040 automotive customers & $\begin{array}{l}\text { Satisfaction-intention link shows decreasing returns. } \\
\text { Satisfaction-behavior link shows increasing return. }\end{array}$ \\
\hline Anderson and Sullivan (1993) & $\begin{array}{l}\text { 22,300 Swedish customers from } 114 \text { companies in } \\
16 \text { industries }\end{array}$ & $\begin{array}{l}\text { Asymmetric impact of quality on repurchase intention. } \\
\text { Elasticity of repurchase intention with respect to satisfaction is } \\
\text { lower for high satisfaction firms. }\end{array}$ \\
\hline
\end{tabular}

Table 2 provides a summary of studies that support this result. Using logistic regression on 100 retail bank customers, of which 21 switched, Rust and Zahorik (1993) find that increasing customer satisfaction (1-5 scale) from 4.2 to 4.7 is likely to increase retention from $95.9 \%$ to $96.5 \%$. Using almost 2,500 telecommunication customers, Ittner and Larcker (1998) infer that a 10-point increase in satisfaction (0-100 scale) increases retention by $2 \%$ and revenues by $\$ 195$ per customer. Using business unit data from 73 retail bank branches, they also demonstrate that satisfaction is positively related to revenues and number of customers.

Bolton (1998) examines duration of relationship of 650 cellular phone customers by tracking their actual behavior over a 22-month period. Using two waves of surveys to get information on satisfaction, she finds that satisfaction is positively related to the duration of relationship, but that it explains only $8 \%$ of the variance. Hallowell (1996) studies 12,000 customers from 59 divisions of a retail bank and also finds that satisfaction is positively related to retention and length of tenure. Unlike Bolton, however, he finds that satisfaction explains as much as $37 \%$ of the variance of customer retention and duration.

Loveman (1998), with data from 45,000 customers across 450 bank branches, shows that satisfaction is positively related to customer retention, number of services used by a customer (cross-sell), and customer share-of-wallet. He further finds that customer satisfaction has the biggest impact on cross-selling. In contrast, Verhoef et al. (2001) use data from more than 2,000 insurance customers over two time periods and conclude that there is no main effect of satisfaction on cross-buying. Consistent with Bolton (1998), however, they find that as relationship length increases, the effect of satisfaction on cross-buying increases.

Using insurance data, Verhoef et al. (2002) test the impact of trust, commitment, and satisfaction on customer referrals and number of services purchased (or cross-selling). While trust, affective commitment, and satisfaction are positively related to customer referrals, only affective commitment has a positive impact on the number of services purchased.

Generalization 5. While customer satisfaction and service quality are strongly correlated with behavioral intentions, behavioral intentions imperfectly predict actual behavior.

Published research offers strong evidence that customer satisfaction and service-quality perceptions affect customer intentions in positive ways-praising the firm, preferring the company over others, increasing the volume of purchases, or agreeing to pay a price premium. A series of studies (Parasuraman et al. 1988, 1994; Cronin and Taylor 1992) find a 
positive and significant relationship between customers' perceptions of service quality and their willingness to recommend the company. Other studies find significant associations between patient satisfaction and intent to choose a hospital again (Woodside et al. 1989) and between service quality, repurchase intentions, and willingness to recommend (Boulding et al. 1993).

Individual companies have also monitored the impact of service quality on selected behavioral intentions. Toyota finds that intent to repurchase a Toyota automobile increases from a base of $37 \%$ to $45 \%$ with a positive sales experience, from $37 \%$ to $79 \%$ with a positive service experience, and from $37 \%$ to $91 \%$ with both positive sales and positive service experiences (McLaughlin 1993). A similar study by Gale (1992) quantitatively assesses the relationship between level of service quality and willingness to purchase at AT\&T. Of AT\&T's customers who rate the company's overall quality as excellent, more than $90 \%$ express willingness to purchase from AT\&T again. For customers rating the service as good, fair, or poor, the percentages decrease to $60 \%, 17 \%$, and $0 \%$, respectively. According to these data, willingness to repurchase increases at a steeper rate, i.e., by $43 \%$ as the service-quality rating improves from fair to good, than when it goes from poor to fair $(17 \%)$ or from good to excellent (30\%). These results suggest that the impact of service quality on willingness to repurchase is most pronounced in some intermediate level of service quality.

When it comes to predicting actual behavior from intentions, however, researchers have found that statements of intentions are not always fulfilled in reality. A large body of theoretical and empirical literature examining the relationship between statements of intent and subsequent behavior (Ajzen 1985, Fishbein and Ajzen 1975) indicates that situational influences and monetary constraints are only two of the many factors that lead intentions to imperfectly predict behavior. Although some studies have shown a positive correlation between intention and actual purchase behavior, their predictive power has been limited (Juster 1966, Kalwani and Silk 1982). Jamieson and Bass (1989) survey 900 consumers over three waves to find their purchase intentions and actual trial of five nondurable and five durable products. They divide consumers into three groups based on their purchase intention-definitely/probably won't buy, might/might not buy, and definitely/probably will buy. Actual trial rates for these groups are $12.6 \%$, $24.3 \%$, and $36.0 \%$ for nondurables, and $4.1 \%, 5.5 \%$, and $10.0 \%$ for durables, respectively. These results show that, while the relationship between intention and actual behavior is positive, significant adjustment is needed to convert intention scores into purchases. Not surprisingly, market research companies routinely use rules of thumb (e.g., top-box or the proportion of people who check the top box on, say, a 5-point scale on a survey; top-box and a half refers to the proportion of people who check the top box and a half of those who check the next box in a survey) to convert intention data into purchase probabilities.

Other research has found that measurement issues affect the relationship between intentions and behavior. Kalwani and Silk (1982) find that the relationship between intentions and behavior is affected by the scale used to measure intentions. Morwitz and Schmittlein (1992) conclude that the relationship varies on the basis of the time horizon used to measure intentions. The link can also be affected by the time lag between intentions and purchase-the longer the lag between measuring intentions and actual purchase, the greater the attenuation of the relationship.

In the context of service profit chain, Loveman (1998) uses data from 450 branches of a bank and finds that, while employee satisfaction is significantly related to employees' stated loyalty, it is not associated with longer job tenure. In contrast, the same study finds that customer satisfaction is positively related to actual customer behavior (retention, shareof-wallet, etc.). Kamakura et al. (2002) examine bank data, also, using a set of structural equations and find a positive path coefficient of 0.27 between customer intentions (willingness to recommend) and customer behavior (bank share, number of transactions).

Another series of studies demonstrates a mere measurement effect: Measuring intent increases the tendency for consumers to increase subsequent purchase behavior (Morwitz et al. 1993, P. Dholakia and Morwitz 2002, U. Dholakia and Morwitz 2002). Individual studies in this stream indicate that the frequency of asking intent influences purchases (Morwitz et al. 1993); that measuring satisfaction changes one-time purchase behavior as well as more stable relationship behaviors such as likelihood of defection and increased product use (U. Dholakia and Morwitz 2002). For this reason, customers who were asked their satisfaction were shown to be more profitable than those who were not asked (P. Dholakia and Morwitz 2002).

Generalization 6. The relationship between unobservable and observable metrics is typically nonlinear.

Why do satisfied customers defect? Jones and Sasser (1995) argue that defection occurs because of a major difference between satisfied and very satisfied customers. While the latter are loyal, the former may defect. Using data from over 100,000 automotive customers, Mittal and Kamakura (2001) confirm that the relationship between satisfaction and actual behavior exhibits increasing returns (i.e., a convex function). They find that a linear model would underestimate the impact of a change in satisfaction score from four 
to five by $64 \%$, causing managers to incorrectly pull back resources from completely satisfied customers. In contrast, the difference between somewhat dissatisfied and very dissatisfied customers is not as large as a linear model suggests. Ittner and Larcker (1998) also find that the relationship between satisfaction and retention is characterized by several satisfaction thresholds that must be reached before retention increases. In contrast to Jones and Sasser (1995) and Mittal and Kamakura (2001), they find that at very high level of satisfaction, retention shows diminishing, rather than increasing returns.

Many studies argue that the relationship between satisfaction and repurchase intention is also nonlinear. Anderson and Sullivan (1993) use a large data set of Swedish customers to show that quality that falls below expectations has a greater impact on satisfaction and repurchase intention than does quality that exceeds expectations. Furthermore, the elasticity of repurchase intention with respect to satisfaction is lower for firms that provide high satisfaction. In other words, long-run reputation effect insulates firms that consistently provide high satisfaction. Anderson and Mittal (2000) use the SCSB to confirm a nonlinear relationship between satisfaction and repurchase intention. Ngobo (1999) examines this relationship in four industries and finds decreasing returns in the insurance industry, two thresholds in camera and bank markets, but a linear relationship in a retail sample.

Several studies also show that the relationship between intentions (repurchase, willingness to recommend) and actual behavior is nonlinear. Using data from more than 5,000 bank customers, Kamakura et al. (2002) show that customers' likelihood to recommend has a nonlinear association with their transactions per month, number of years they stay with the bank, and overall firm profits. However, the relationship with share-of-wallet is linear.

While several researchers confirm the nonlinear relationship between satisfaction and retention (as well as repurchase intention), it is far from clear if this relationship is convex (Jones and Sasser 1995) or concave (Ittner and Larcker 1998). Mittal and Kamakura (2001) show that while the satisfaction-intention link shows decreasing returns, the satisfaction-behavior link shows increasing returns. Furthermore, this relationship seems to vary by the metrics (Kamakura et al. 2002) as well as industry (Ngobo 1999). Significant work is needed in the future before we can arrive at empirical generalizations about the exact nature of this nonlinearity.

\section{Link Between Observable Metrics and Financial Performance}

In this section, we discuss three generalizations about the link between customer metrics and financial per- formance of a firm. The first generalization demonstrates that a focus on observable metrics leads to improved financial performance. The second generalization suggests which metric is the most critical in driving performance.

Finally, the third generalization bridges marketing and finance by linking these customer metrics to the market value of a firm. Linking customer value to firm value is important because it helps to make marketing more accountable and also provides a tool for firm valuation when traditional financial models may not work. When companies do not have measures on cash flow (to do a discounted cash flow model) and earnings (to assess the price-earnings or $\mathrm{P} / \mathrm{E}$ ratio), CLV provides an alternative way to estimate firm value (e.g., Gupta et al. 2004).

Generalization 7. Marketing decisions based on observed customer metrics, such as CLV, improve a firm's financial performance.

At a conceptual level, a link between observable customer metrics, such as CLV, and financial performance of a firm is guaranteed almost by definition. CLV focuses on the long-term profit rather than the short-term profit or market share. Therefore, maximizing CLV is effectively maximizing the long-run profitability and financial health of a company. There are two additional reasons for this strong link. First, decisions based on CLV help in better customer selection. Second, CLV leads to better or optimal allocation of a marketing budget (Berger et al. 2002).

Customers vary dramatically in their overall profitability to a company. This variability is even more than the usual 80-20 rule (the common belief that $80 \%$ of a firm's profits come from the top $20 \%$ of the customers). Several companies have found that this variability is better described as a $220-20$ rule, i.e., that $20 \%$ of the customers provide $220 \%$ of the profits. ${ }^{3}$ In other words, a large number of customers destroy value. This makes customer selection critical. Models of CLV help in the selection of profitable customers (Table 3).

Niraj et al. (2001) study 650 customers of a distributor and find that, based on their CLV model, 32\% customers are unprofitable. Kamakura et al. (2003) examine 5,550 customers of a Brazilian bank and find that the top $30 \%$ cross-selling prospects of phone banking cards have predicted usage probability of greater than $80 \%$. Li et al. (2005) build a cross-selling model for 1,201 bank customers. They show that, while a randomly drawn group that constitutes $10 \%$ of the sample will, on average, contain $10 \%$ of the overall purchases, the top $10 \%$ of customers as selected by their model

${ }^{3}$ See, for example, Harvard Business School case studies on Kanthal (Case \# 9-190-002) and Pilgrim Bank (Case \# 9-602-104). 


\begin{tabular}{|c|c|c|}
\hline Study & Data & Results \\
\hline Niraj et al. (2001) & 650 customers of a distributor & $32 \%$ customers were unprofitable. \\
\hline Kamakura et al. (2003) & 5,550 customers of a Brazilian bank & Top $30 \%$ customers have more than $80 \%$ usage probability. \\
\hline Li et al. (2005) & 1,201 customers of a bank & $\begin{array}{l}\text { Top } 10 \% \text { customers account for almost } 50 \% \text { of all } \\
\text { purchases. }\end{array}$ \\
\hline Reinartz and Kumar (2003) & 11,992 households, three years from a catalog retailer & $\begin{array}{l}33 \% \text { higher revenue from top } 30 \% \text { customers based on } \\
\text { CLV vs. RFM model. }\end{array}$ \\
\hline Venkatesan and Kumar (2004) & $\begin{array}{l}\text { Two cohorts ( } 1,316 \text { and } 873 \text { customer) from computer } \\
\text { hardware, software manufacturer }\end{array}$ & $\begin{array}{l}10 \%-50 \% \text { higher profit from top } 5 \% \text { customers based on } \\
\text { CLV vs. RFM model. }\end{array}$ \\
\hline Malthouse and Blattberg (2005) & $\begin{array}{l}71,381 \text { customers from a service company } \\
68,026 \text { customers from nonprofit, } \\
24,047 \text { customers from B2B } \\
41,669 \text { customers from catalog } \\
3,000 \text { to } 95,000 \text { customers from } 131 \text { companies }\end{array}$ & $\begin{array}{l}\text { Of the top } 20 \% \text { customers, } 55 \% \text { misclassified. } \\
\text { Of the bottom } 80 \% \text { customers, } 15 \% \text { misclassified. }\end{array}$ \\
\hline Donkers et al. (2003) & 1.3 million insurance customers for 1998-2001 & Mean prediction error in CLV models $=17 \%$. \\
\hline Reinartz et al. (2005) & 12,024 prospects of a B2B company & $\begin{array}{l}\text { CLV model-based allocation: } 68.3 \% \text { reduction in marketing } \\
\text { expense } \rightarrow 41.5 \% \text { increase in profit. } \\
25 \% \text { underspending on retention } \rightarrow 55 \% \text { drop in ROI. } \\
25 \% \text { underspending on acquisition } \rightarrow 3 \% \text { drop in ROI. }\end{array}$ \\
\hline Thomas et al. (2004) & Pharma and catalog retailers & $\begin{array}{l}\text { Catalog: } 30.7 \% \downarrow \text { spend } \rightarrow 28.9 \% \uparrow \text { profit } \\
\text { Budget: retention }=86 \% \text {, acquisition }=16 \% \\
\text { Pharma: } 31.4 \% \uparrow \text { spend } \rightarrow 35.8 \% \uparrow \text { profit }\end{array}$ \\
\hline Lewis (2005a) & 1,326 current and prospective customers of a newspaper & Optimal pricing policy improves CLV by $13.9 \%$ \\
\hline Knott et al. (2002) & $\begin{array}{l}24,000-50,000 \text { retail bank customers in three groups for } \\
\text { field test }\end{array}$ & $\begin{array}{l}\text { ROI from cross-selling model }=530 \% \\
\text { ROI from heuristic }=-17 \% \\
\text { ROI from purchased list }=-30 \%\end{array}$ \\
\hline Simester et al. (2006) & $\begin{array}{l}\text { Catalog retailer, } 1.73 \text { million customers during } \\
\quad 1996-2002 \\
\text { Field test on } 60,000 \text { customers }\end{array}$ & $\begin{array}{l}\text { Difference in profit for treatment and control group } \\
\text { Low-value customer }=7 \% \\
\text { Moderate-value customer }=10 \% \\
\text { High-value customer }=-16 \%\end{array}$ \\
\hline Reichheld and Sasser (1990) & Several service industries & $\begin{array}{l}5 \% \text { improvement in customer retention } \rightarrow 25 \%-85 \% \\
\text { improvement in profit. }\end{array}$ \\
\hline Coyles and Gokey (2002) & 1,600 households in 16 industries & $\begin{array}{l}5 \% \text { defection } \rightarrow 3 \% \downarrow \text { balance of a bank. } \\
35 \% \text { customers reduce balance } \rightarrow 24 \% \downarrow \text { balance for } \\
\text { the bank. }\end{array}$ \\
\hline Kim et al. (1995) & Cellular phone industry & $\begin{array}{l}\text { Links market penetration (subscribers) to market value for } \\
\text { the industry. }\end{array}$ \\
\hline Gupta et al. (2004) & $\begin{array}{l}\text { Publicly available data for Amazon, Ameritrade, Etrade, } \\
\text { Capital One, and eBay }\end{array}$ & $\begin{array}{l}\text { Value of customers for the industry provides a good proxy } \\
\text { for firm value. } \\
1 \% \text { improvement in retention, increases firm value by } 5 \% \text {. }\end{array}$ \\
\hline Libai et al. (2005) & Same as Gupta et al. (2004) & Customer value provide a good proxy for firm value. \\
\hline Rust et al. (2004) & $100-137$ customer surveys in five industries & Firm actions $\rightarrow \mathrm{CE} \rightarrow \mathrm{ROI}$ \\
\hline
\end{tabular}

contain almost $50 \%$ of the purchases. Reinartz and Kumar (2003) use a catalog retailer's data of almost 12,000 customers over three years and compare several models. They find that the revenue from the top 30\% customers based on their CLV model is 33\% higher than the top 30\% customers selected, based on an RFM model. Venkatesan and Kumar (2004) also compare several competing models for customer selection. Using data on almost 2,000 customers for a computer hardware and software manufacturer, they find that the models vary significantly in their customer selection. Specifically, the profit generated by the top 5\% customers as selected by the CLV model is $10 \%-50 \%$ higher than the profit from the top $5 \%$ customers of other models (such as RFM, customer lifetime duration, past value).

These studies confirm the value of CLV-based models in better selection of profitable customers. This selection in turn improves the overall financial performance of a firm. Since none of these studies use a real field test to compare the model predicted profit with the actual profit realized in the marketplace, they are based on the implicit assumption that it is indeed possible to accurately predict future profitability of the customers. Malthouse and Blattberg (2005) challenge this assumption. Using a wide range of large data sets they build regression-based models of CLV using approximately two years of data. They then use about three years of future data for assessing the 
accuracy of predictions. Their results show that $55 \%$ of the top $20 \%$ customers and $15 \%$ of the bottom $80 \%$ customers were misclassified. Given the focus of most CLV-based models to predict the best customers, they question the ability of these models to actually predict future profitability of customers. In contrast, Donkers et al. (2003) use insurance data of 1.3 million customers for three years to conclude that most CLV models predict quite well (mean error is about $17 \%$ ). It is possible that the difference in the accuracy of predictions is related to the nature of the model. This issue needs further investigation.

The second reason for CLV-based decisions to improve financial performance is their ability to better allocate marketing resources. Using data of about 12,000 prospects of a B2B manufacturer, Reinartz et al. (2005) show that when budgets are allocated as per the CLV model, marketing spending goes down by $68.3 \%$ and profits go up by $41.5 \%$. Thomas et al. (2004) confirm these results for two other applications. They show that as per the CLV model, a pharmaceutical company should spend $31.4 \%$ more on marketing that will improve its profits by $35.8 \%$, while a catalog retailer should cut its marketing budget by $30.7 \%$ to boost its profits by $28.9 \%$. Lewis (2005a) uses data of 1,326 active and prospective customers of a major newspaper to suggest an optimal pricing path that maximizes customer value. His results show that, compared to a simple two-pricing structure (where a low introductory price is followed by a higher regular price), an optimal pricing policy improves customer value by almost $14 \%$.

The studies mentioned above predict an improvement in profits but don't actually show it in the field. Several studies have taken this next step. In the context of cross-selling loan products for customers of a retail bank, Knott et al. (2002) develop a cross-selling model. In addition to performing the usual validation tests, they also conducted a field test. In this test, they created three main groups of 24,000 to 50,000 customers. The first group was selected based on the cross-selling model developed by the authors. The second group included customers who were selected using the bank's heuristic. The third group consisted of noncustomers of the bank based on the names purchased from a list broker. The field test results show that the ROI of the model-based group was $530 \%$, while that for the other two groups was $-17 \%$ and $-30 \%$, respectively. Simester et al. (2006) used 1.73 million customers of a catalog retailer to develop an optimal catalog mailing policy. They then tested their model in the field with 60,000 customers. These customers were divided into low-, medium-, and high-value customers (as per the model-based value). Customers in each group were randomly assigned to the treatment (optimal) or control (company policy) group. Differences in the profit of the treatment and control groups for each of the three customer value groups were recorded after six months. Results show that, compared to the control groups, the treatment groups did significantly better for low $(+7 \%$ profit difference) and medium $(+10 \%)$ value groups, but not for the high $(-16 \%)$ value group. These results may resonate with Malthouse and Blattberg (2005), who also find it hard to correctly classify the best customers.

In addition to the academic studies, there are a handful of practical case studies that also demonstrate the rewards of focusing on customer metrics. A good example of this is Harrah's Entertainment Inc. that drove its entire business based on observable customer metrics such as theoretical win (similar to CLV) and share-of-wallet. While it is difficult to isolate the impact of this focus on its stellar financial performance, its CEO Gary Loveman argues that this focus played a major role (Loveman 2003).

Generalization 8. Customer retention is one of the key drivers of CLV and firm profitability.

CLV is affected by acquisition cost, customer retention, and margin (hence, cross-selling). Several studies show that customer retention is the most critical of these variables. Reichheld and Sasser (1990) show that a $5 \%$ improvement in customer retention for a variety of service companies could improve their overall profitability by anywhere from $25 \%$ to $85 \%$. Reichheld (1996) further confirms the importance of retention based on a series of real-life studies conducted by Bain \& Company. Gupta et al. (2004) examine five companies and also find that retention is more important than margin or acquisition cost. Specifically, they find that a $1 \%$ improvement in retention can improve customer profitability by about 5\%, while a similar improvement in margin and acquisition cost improves profits by $1.1 \%$ and $0.1 \%$, respectively.

Reinartz et al. (2005) find that suboptimal allocation of retention expenditure has a greater detrimental effect on CLV than a suboptimal allocation of acquisition budget. In their application for a B2B manufacturer, they find that $25 \%$ underspending on retention reduces $\mathrm{ROI}$ by about $55 \%$, while similar underspending on acquisition reduces ROI by only about 3\%. Consequently, their optimal budget allocation was $79 \%$ retention and $21 \%$ acquisition. Thomas et al. (2004) find a similar result for a pharmaceutical company where the optimal budget allocation turns out to be $86 \%$ retention and $14 \%$ acquisition.

Some researchers argue that retention may not be critical in all situations. Coyles and Gokey (2002) study 1,600 households across 16 industries and find that margins and cross-selling may be more critical than retention in many industries. For example, 
they report that in retail banking only $5 \%$ of customers with checking accounts defect annually, leading to a $3 \%$ reduction in the deposit balances for the bank. In contrast, 35\% of customers reduce their balances, adversely affecting bank balances by $24 \%$. Keiningham et al. (2005) also question Reichheld and Sasser's (1990) results by showing that their findings will hold only if the profit margins for a firm are very low (e.g., 5\%) or if the firm has a fairly high retention rate to begin with (when cost of improving retention will be larger). Finally, we believe that the allocation of retention and acquisition budget depends on the life cycle of a product and industry. For example, in high growth markets such as India and China, it may make more sense to focus on customer acquisition instead of retention.

Generalization 9. Customer metrics, especially CLV and $C E$, provide a good basis to assess the market value of a firm.

This is a relatively new topic and therefore only a limited number of studies exist in this area. Nonetheless, they all point in the same direction. Kim et al. (1995) use subscriber data in the cellular phone industry to estimate the value per pop (i.e., the number of people living in a service area). They find that their model is able to capture and predict this value quite well. While Kim et al. (1995) use the basic elements of customer metrics (e.g., number of subscribers) to assess value at the industry level, they do not incorporate customer retention, which is critical in the valuation of a firm. Gupta et al. (2004) use publicly available customer data for five firms to estimate their customer equity (i.e., value of their current and future customers). They find that their customer value estimates are close to the market value for three of the five firms (exceptions were Amazon and eBay).

Libai et al. (2005) use a Bass diffusion model with customer defection and replicate the customer valuation for the same five firms examined by Gupta et al. (2004). Their results confirm the findings of Gupta et al. (2004). Rust et al. (2004) use a survey of 100 customers for airlines to estimate CLV for American Airlines. Using this estimate and the total number of airline passengers, they estimate the overall customer value of American Airlines in 1999 as $\$ 7.3$ billion. Considering that this estimate does not include international traffic and other nonflight sources of revenue, it is reasonably close to the $\$ 9.7$ billion market value of American Airlines at that time.

\section{Future Challenges}

We indicated several controversies and potential areas of research during our discussion in $\$ \S 4-6$. For example, many studies indicate that the link between satisfaction and retention is nonlinear, but there is conflicting evidence concerning whether this relationship is convex or concave. Similarly, some studies show that customer lifetime is difficult to predict, while others demonstrate that it is indeed possible. These conflicting results provide avenues for future research. In this section, we highlight additional areas of research.

\subsection{Research on Unobservable or Perceptual Metrics}

Do We Need All the Perceptual Constructs? Conducting this survey of customer metrics has made one thing very clear: Considerable overlap exists in definition and measurement of the constructs on which perceptual customer metrics are based. Although research defines and operationalizes the concepts differently, strong correlations are present among the perceptual metrics we focused on (customer satisfaction, service quality, loyalty, and intention to purchase) and those we chose to eliminate (perceived value, commitment). Many research studies have examined different pairs or combinations of variables, and the pattern of relationships among the variables is not clear. For example, more than 30 empirical studies measure both service quality and customer satisfaction, many of them in an effort to differentiate the constructs from each other and determine the directionality of the relationship between them. While some academic researchers have acknowledged the interchangeability of the constructs (Rust et al. 1995), most have attempted to be precise about the differences between service quality and customer satisfaction, resulting in considerable debate (Parasuraman et al. 1994, Cronin et al. 2000).

\subsection{Research on Observable or Behavioral Metrics}

Accounting for Network Effects. Most of the research on CLV has implicitly assumed that the value of a customer is independent of other customers. In many situations, customer network effects can be strong, and ignoring them may lead to underestimating CLV. Hogan et al. (2003) show that word-of-mouth or direct network effects can be substantial for online banking. In many situations, there are also strong indirect network effects. For example, firms such as eBay and Monster have two related populations (buyers and sellers, or job seekers and employers). The growth in one population affects the growth in the other populations, and vice versa. Hogan et al. (2002) also suggest more research in this direction. With the rise of online communities such as MySpace, online conversation may offer an easy and cost-effective opportunity to measure word-of-mouth communication and customer satisfaction (Godes and Mayzlin 2004). 
Modeling Retention Using Different Approaches.

The empirical literature in marketing has traditionally favored structured parametric models (such as logistic or probit regression or parametric hazard specifications) that are easy to interpret. In contrast, the vast literature in data mining, machine learning, and nonparametric statistics has generated a plethora of approaches that emphasize predictive ability. These include projection-pursuit models, neural network models, tree structured models, spline-based models such as generalized additive models (GAM), and multivariate adaptive regression splines (MARS), and more recently approaches such as support vector machines and boosting. These machine-learning approaches remain alien to the marketing literature, not surprisingly because of the tremendous emphasis that marketing academics place on substantive insights and interpretability. Predictions can also be improved by combining models. The machine-learning literature on bagging, the econometric literature on the combination of forecasts, and the statistical literature on model averaging suggest that weighting the predictions from many different models can yield improvements in predictive ability (Lemmens and Croux 2005, Neslin et al. 2006). Further work is needed to understand the relative merits and disadvantages of these different approaches.

Impact of Cross-Selling on Retention. Many firms believe that cross-selling improves customer retention. In other words, customers who buy multiple products from a firm are likely to be more loyal. This may indeed be true. However, the evidence to date is generally correlational. Causality may, in fact, go in the opposite direction, i.e., customers who are more loyal to a firm may tend to buy multiple products, instead of the other way around. If cross-selling does indeed enhance customer loyalty, then it also has strong implications for pricing of subsequent products sold to a customer. Almost no research has been done in this area.

Accounting for Endogeneity. Customer metrics help a firm identify high- and low-value customers as well as design appropriate customer offers. For example, catalog companies group customers into deciles based on their past purchase behavior, and the most responsive or high-value group receives more catalogs than the low-value group. Similarly, in the airline industry frequent fliers receive better treatment than infrequent fliers-low-value customers get lower service levels, lower status in the loyalty programs, and lower overall benefits.

This could be a self-fulfilling prophecy where low levels of investments in customers lead to lower customer profitability, which in turn leads to an even lower level of investment from the firm. In other words, customers are not only responding to firms' actions, but also firms are responding to the behavior of customers. Most customer metrics and models ignore this endogeneity issue and instead assume that an individual customer's value over his lifetime is given. Our task as researchers is to estimate the endogeneity and use this estimate to provide service that is commensurate with the value of a customer.

Accounting for Competition. It is ironic that, even as company databases are growing larger and models are becoming more sophisticated, they ignore competition and thus provide an incomplete and sometimes misleading picture. For example, the service quality of a firm may be improving over time but may have no impact on customer satisfaction if the service quality of competitors is improving even faster. Similarly, two customers with the same CLV may have different shares-of-wallet and therefore different potential. While customer defection clearly depends on competitive offerings, most models of customer defection do not include such information.

A few studies have found innovative ways to avoid these problems. For example, Kamakura et al. (2003) supplement a bank's internal customer database with a survey of a few thousand customers. Since it is impossible to survey millions of bank customers, they use the data from the survey sample to impute the missing information (e.g., share-of-wallet) for the remaining customers in the database. We need more studies that either use such innovative methods to account for competition, or that show the potential bias from ignoring this information.

\subsection{Research on the Links}

Incorporate Perceptual Constructs in Behavioral Outcome Models. In spite of the popularity of perceptual measures (e.g., customer satisfaction) among academics and practitioners, it is surprising to find that few studies have directly incorporated them in the behavioral outcome (e.g., CLV) models. There are at least three reasons for this lack of connection. First, in academia there are two parallel groups of researchers: those who primarily work with perceptual measures and those that focus mainly on behavioral outcomes, with little interaction between the two groups. This is often also true in companies, where groups of researchers silo their customer data (e.g., a marketing research group deals with complex modeling techniques and a customer satisfaction group deals with survey feedback). Second, perceptual data are usually collected for a sample of customers through surveys, whereas behavioral data are available for all customers based on transaction data. Merging the databases requires handling of missing observations for the majority of customers. Third, survey data are often collected anonymously, making it 
difficult if not impossible for researchers to connect it with behavioral data.

Satisfaction as a Leading Indicator of Future Behavior and Financial Performance. As indicated in $\S \S 4$ and 5, satisfaction is strongly correlated with behavioral outcome and financial performance. However, almost all these studies use cross-sectional data. Mazursky and Geva (1989) find that satisfaction and intentions are highly correlated when measured in the same survey (time $t_{1}$ ). However, they find that for the same subjects, satisfaction at $t_{1}$ has no correlation with intentions after a two-week interval $\left(t_{2}\right)$. In a longitudinal study, Mittal et al. (1999) find that the relationship between satisfaction and behavioral intentions can increase or decrease over time. They contend that estimates based on a single cross-section alone can be misleading, and that the type of behavior intent (e.g., purchase versus recommend) can affect the strength of the relationship. In a largescale study, Bernhardt et al. (2000) study more than 342,000 consumer responses from 472 restaurants over a 12-month period. They find that customer satisfaction at time $t_{1}$ has no impact on financial performance of a restaurant at $t_{1}$. However, they find a significant impact of change in customer satisfaction during time $t$ and $t+1$ on change in a restaurant's profits during time $t+1$ and $t+2$. Specifically, restaurants with change in satisfaction of more than 0.1 above an average restaurant has more than $30 \%$ improvement in profit over an average performer. Unfortunately, Mittal et al. (1999) and Bernhardt et al. (2000) are two of the few studies that provide this time-series perspective. Cross-sectional studies, while useful, may suffer from endogeneity bias. More longitudinal studies will not only help alleviate this problem, but may also be able to establish satisfaction as a leading indicator of a firm's financial performance. While there are a handful of studies that take this perspective, we need more research in this area to enable us to make generalizations.

Determine the Functional Form of the Relationship Between Satisfaction and Profitability. As described in G2, several studies have established the asymmetric and nonlinear nature of the link between satisfaction and profitability. However, the exact form of this nonlinearity needs further research. For example, Anderson and Mittal (2000) find that a drop in satisfaction produces twice the impact on ROI as does an increase in satisfaction. In contrast, Nayyar (1995) finds negative news of customer service has only half the impact on CAR as does the positive news. Future research should examine theoretically and empirically the nature of this asymmetry.
Identify the Reasons for Different Customer Satisfaction Results Across Industries. Several studies described in Generalization 3 (G3) find significant differences in the satisfaction and profitability relationship across industries. Two important research questions are raised by these findings. First, do some industries systematically show a stronger link between satisfaction and profitability than other industries? Anderson et al. (2004) find wide variation in the strength of the link across 23 industries. Ittner and Larcker (1998) find a negative link in the retail industry, while Anderson et al. (2004) show the strongest positive link in the same industry. Second, why is this link stronger for some industries than others? Although we have some initial results, we need more studies that relate industry characteristics to strengthen this relationship.

Build Comprehensive Models of Service-Profit Chain. Kamakura et al. (2002) is one of the few studies to take a comprehensive view of customer metrics that includes unobservable, observable, and financial measures. The authors empirically investigate the service profit chain that links operational inputs (e.g., investment in personnel or ATMs in a bank), customers' perceptions, customers' behavior, and firm profit. We need more studies that view customer metrics comprehensively, rather than examining only a few constructs at a time. These studies can help us understand how the constructs in Figure 1 are related, which constructs mediate others, which constructs lag or lead other constructs, and how these relationships change by contexts and industries. This should eventually lead to robust empirical generalizations.

Linking Customer and Brand Metrics. For more than a decade, marketing has focused heavily on brand equity. The marketing literature developed its own set of perceptual (e.g., awareness, association, and attachment), behavioral (e.g., price sensitivity) and financial (e.g., brand value) metrics. Many academic studies show that brand equity forms a large part of a firm value. Companies such as Interbrand routinely estimate the financial value of brands. Even accountants have taken notice of the intangible value of brands, and there is currently a debate about putting these intangible assets on the balance sheet. At the same time, research on customer metrics has developed its own set of perceptual, behavioral, and financial metrics.

However, the two streams have grown almost independent of each other. Each stream uses its own set of metrics and is rarely linked to the other. Many researchers are confused about the difference between brand equity and CE. Is one a subset of the other? Does brand equity affect $\mathrm{CE}$, or is it the other way around? Is it possible for a firm to have low brand 
equity but high CE, and vice versa? Rust et al. (2004) suggest that brand value is one of the components of CE. However, more work is needed to clarify the distinction and relation between these two important areas.

\section{Conclusion}

In this paper, we set out to review and integrate existing knowledge on customer metrics. We provided a simple yet comprehensive framework for customer metrics, examined unobservable and observable metrics, and made nine empirical generalizations about the relationship between these metrics and firm profitability. We also highlighted future research challenges to address because firms feel an everincreasing need to justify their investment in customers. Firms must demonstrate the link among their actions, customer behavior, and their financial performance. Our review and research agenda provide a foundation for these relationships. Our hope is that researchers will continue to move the field forward by further clarifying these relationships.

\section{Acknowledgments}

The authors are grateful for the comments by Eugene Anderson, Asim Ansari, Robert Blattberg, Shirish Dant, Melinda Denton, Donald R. Lehmann, Leigh McAlister, J. B. Steenkamp, Earl Taylor, Susan Toner, and participants of the Marketing Science Institute Research Generation Conference in Atlanta. They thank Ricardo Montoya for his research assistance.

\section{References}

Aaker, David, Robert Jacobson. 1994. The financial information content of perceived quality. J. Marketing Res. 31(2) 191-201.

Ajzen, Icek. 1985. From intentions to actions: A theory of planned behavior. Julius Kuhl, Jurgen Bechmann, eds. Action Control: From Cognition to Behavior. Springer, Heidelberg, Germany, 11-39.

Allenby, Greg, Robert Leone, Lichung Jen. 1999. A dynamic model of purchase timing with application to direct marketing. J. Amer. Statist. Assoc. 94(446) 365-374.

Anderson, Eric, Duncan Simester. 2004. Long-run effects of promotion depth on new versus established customers: Three field studies. Marketing Sci. 23(1) 4-20.

Anderson, Eugene W., V. Mittal. 2000. Strengthening the satisfaction-profit chain. J. Service Res. 3(2) 107-120.

Anderson, Eugene W., Mary Sullivan. 1993. The antecedents and consequences of customer satisfaction for firms. Marketing Sci. 12(Spring) 125-143.

Anderson, Eugene W., Claes Fornell, Donald R. Lehmann. 1994. Customer satisfaction, market share, and profitability: Findings from Sweden. J. Marketing 58(3) 53-66.

Anderson, Eugene W., Claes Fornell, Sanal Mazvancheryl. 2004. Customer satisfaction and shareholder value. J. Marketing 68(4) 172-185.

Anderson, Eugene W., Claes Fornell, Roland Rust. 1997. Customer satisfaction, productivity, and profitability: Differences between good and services. Marketing Sci. 16(2) 129-145.
Berger, Paul, Ruth Bolton, Douglas Bowman, Elten Briggs, V. Kumar, A. Parasuraman, Creed Terry. 2002. Marketing actions and the value of customer assets: A framework for customer asset management. J. Service Res. 5(1) 39-54.

Bernhardt, Kenneth, Naveen Donthu, Pamela Kennett. 2000. A longitudinal analysis of satisfaction and profitability. J. Bus. Res. 47(2) 161-171.

Bitran, Gabriel, Susana Mondschein. 1996. Mailing decisions in the catalog sales industry. Management Sci. 42(9).

Blattberg, Robert, Gary Getz, Jacquelyn S. Thomas. 2001. Customer Equity: Building and Managing Relationships as Valuable Assets. Harvard Business School Press, Boston, MA.

Bolton, Ruth N. 1998. A dynamic model of the duration of the customer's relationship with a continuous service provider: The role of satisfaction. Marketing Sci. 17(1) 46-65.

Bolton, Ruth N., James H. Drew. 1991. A longitudinal analysis of the impact of service changes on customer attitudes. J. Marketing 55(Jan.) 1-9.

Bolton, Ruth, P. K. Kannan, Matthew Bramlett. 2000. Implications of loyalty program membership and service experiences for customer retention and value. J. Acad. Marketing Sci. 28(1) 95-108.

Boulding, William, Ajay Kalra, Richard Staelin, Valarie Zeithaml. 1993. A dynamic process model of service quality: From expectations to behavioral intentions. J. Marketing Res. 30(Feb.) 7-27.

Buzzell, Robert, Bradley Gale. 1987. The PIMS Principles. The Free Press, New York.

Cadotte, Ernest, Robert Woodruff, Roger Jenkins. 1987. Expectations and norms in models of consumer satisfaction. J. Marketing Res. 24(Aug.) 305-314.

Coyles, Stephanie, Timothy Gokey. 2002. Customer retention is not enough. McKinsey Quart. 2 81-89.

Cronin, Joseph, Steven Taylor. 1992. Measuring service quality: A reexamination and extension. J. Marketing 56(July) 55-68.

Cronin, Joseph, Michael K. Brady, G. Tomas Hult. 2000. Assessing the effects of quality, value, and customer satisfaction on consumer behavioral intentions in service environments. J. Retailing 76(2) 193-218.

Dholakia, Paul, Vicki Morwitz. 2002. How surveys influence customers. Harvard Bus. Rev. 80(May) 18-19.

Dholakia, Utpal, Vicki Morwitz. 2002. The scope and persistence of mere-measurement effects: Evidence from a field study of customer satisfaction measurement. J. Consumer Res. 29(Sept.) 159-167.

Donkers, Bas, Peter Verhoef, Martijn de Jong. 2003. Predicting customer lifetime value in multi-service industries. Working paper, Erasmus University Rotterdam, The Netherlands.

Dowling, Grahame R., Mark Uncles. 1997. Do customer loyalty programs really work? Sloan Management Rev. 38(4) 71-82.

Drèze, Xavier, André Bonfrer. 2005. Moving from customer lifetime value to customer equity. Working paper, University of Pennsylvania, Philapelphia, PA.

Dwyer, F. Robert. 1997. Customer lifetime valuation to support marketing decision making. J. Interactive Marketing 11(4) 6-13.

Fader, Peter, Bruce Hardie, Ka Lee. 2005. RFM and CLV: Using isovalue curves for customer base analysis. J. Marketing Res. 42(4) 415-430.

Fishbein, Martin, Icek Ajzen. 1975. Belief, Attitude, Intention and Behavior. Addison-Wesley, Reading, MA.

Frei, Frances, Denis Campbell. Pilgrim Banks (A): Customer profitability. Case 9-602-104, Harvard Business School, Cambridge, MA.

Gale, Bradley. 1992. Monitoring customer satisfaction and marketperceived quality. Worth Repeating Series 922CSO1. American Marketing Association, Chicago, IL. 
Garbarino, Ellen, Mark S. Johnson. 1999. The different roles of satisfaction, trust, and commitment in customer relationships. J. Marketing 63(April) 70-87.

Godes, David, Dina Mayzlin. 2004. Using online conversation to study word-of-mouth communication. Marketing Sci. 23(4) $545-560$.

Gonul, Fusun, Mengze Shi. 1998. Optimal mailing of catalogs: A new methodology using estimable structural dynamic programming models. Management Sci. 44(9) 1249-1262.

Gonul, Fusun, Byung-Do Kim, Mengze Shi. 2000. Mailing smarter to catalog customers. J. Interactive Marketing 14(2) 2-16.

Gruca, Thomas S., Loopo L. Rego. 2005. Customer satisfaction, cash flow and shareholder value. J. Marketing 69(July) 115-130.

Gruen, Thomas W., John O. Summers, Frank Acito. 2000. Relationship marketing activities, commitment and membership behaviors in professional associations. J. Marketing 64(3) 34-49.

Guadagni, Peter, John Little. 1983. A logit model of brand choice calibrated on scanner data. Marketing Sci. 2(3) 203-238.

Gupta, Sunil. 1988. Impact of sales promotions on when, what, and how much to buy. J. Marketing Res. 25(4) 342-355.

Gupta, Sunil, Donald R. Lehmann. 2003. Customers as assets. J. Interactive Marketing 17(1) 9-24.

Gupta, Sunil, Donald R. Lehmann. 2005. Managing Customers as Investments. Wharton School Publishing, Upper Saddle River, NJ.

Gupta, Sunil, Donald R. Lehmann, Jennifer Ames Stuart. 2004. Valuing customers. J. Marketing Res. 41(1) 7-18.

Hallowell, Roger. 1996. The relationships of customer satisfaction, customer loyalty, and profitability: An empirical study. Internat. J. Service Indust. Management 7(4) 27-42.

Hansotia, Behram, Paul Wang. 1997. Analytical challenges in customer acquisition. J. Direct Marketing 11(2) 7-19.

Hogan, John E., Katherine N. Lemon, Barak Libai. 2003. What is the true value of a lost customer? J. Service Res. 5(3) 196-208.

Hogan, John E., Donald R. Lehmann, Maria Merino, Rajendra K. Srivastava, Jacquelyn Thomas, Peter Verhoef. 2002. Linking customer assets to financial performance. J. Service Res. 5(1) 26-38.

Ittner, Christopher, David F. Larcker. 1996. Measuring the impact of quality initiatives on firm financial performance. Soumeh Ghosh, Donald Fedor, eds. Advances in the Management of Organizational Quality, Vol. 1. JAI Press, Greenwich, CT, 1-37.

Ittner, Christopher, David Larcker. 1998. Are non-financial measures leading indicators of financial performance? An analysis of customer satisfaction. J. Accounting Res. 36(3) 1-35.

Iyengar, Raghuram. 2004. A structural demand analysis of wireless services under nonlinear pricing schemes. Working paper, Columbia University, New York.

Iyengar, Raghuram, Asim Ansari, Sunil Gupta. 2003. Leveraging information across categories. Quant. Marketing Econom. 1(4) 425-446.

Jacoby, Jacob, Robert Chestnut. 1978. Brand Loyalty: Measurement and Management. John Wiley \& Sons, New York.

Jain, Dipak, Siddhartha Singh. 2002. Customer lifetime value research in marketing: A review and future directions. J. Interactive Marketing 16(2).

Jamieson, Linda, Frank Bass. 1989. Adjusting stated intention measures to predict trial purchase of new products: A comparison of models and methods. J. Marketing Res. 26(Aug.) 336-345.

Jones, Thomas, Earl Sasser. 1995. Why satisfied customers defect. Harvard Bus. Rev. 73(Nov.-Dec.) 88-99.

Joshi, Amit, Dominique Hanssens. 2005. Advertising spending and market capitalization. Working paper, Anderson School of Management, University of California, Los Angeles, CA.
Juster, Thomas. 1966. Consumer buying intentions and purchase probability: An experiment in survey design. J. Amer. Statist. Assoc. 61(Sept.) 658-697.

Kalbfleisch, John, Ross Prentice. 1980. Statistical Analysis of Failure Time Data. Wiley, New York.

Kalwani, Manohar, Alvin Silk. 1982. On the reliability and predictive validity of purchase intention measures. Marketing Sci. 1(Summer) 243-286.

Kamakura, Wagner, Bruce Kossar, Michael Wedel. 2004. Identifying innovators for the cross-selling of new products. Management Sci. 50(8) 1120-1133.

Kamakura, Wagner, Sridhar Ramaswami, Rajendra Srivastava. 1991. Applying latent trait analysis in the evaluation of prospects for cross-selling of financial services. Internat. J. Res. Marketing 8(3) 329-349.

Kamakura, Wagner, Vikas Mittal, Fernando de Rosa, Jose Afonso Mazzon. 2002. Assessing the service-profit chain. Marketing Sci. 21(3) 294-317.

Kamakura, Wagner, Michel Wedel, Fernando de Rosa, Jose Afonso Mazzon. 2003. Cross-selling through database marketing: A mixed data factor analyzer for data augmentation and prediction. Internat. J. Res. Marketing 20(1) 45-65.

Kamakura, Wagner, Carl Mela, Asim Ansari, Anand Bodapati, Pete Fader, Raghuram Iyengar, Prasad Naik, Scott Neslin, Baohong Sun, Peter Verhoef, Michel Wedel, Ron Wilcox. 2006. Choice models and customer relationship management. Marketing Lett. 16(4) 279-291.

Kaplan, Robert. 2001. Kanthal (A). Case 9-190-002, Harvard Business School, Cambridge, MA.

Keiningham, Timothy, Terry Vavra, Lerzan Aksoy, Henri Wallard. 2005. Loyalty Myths. John Wiley \& Sons, NJ.

Kim, Keysuk, Gary L. Frazier. 1997. Measurement of distributor commitment in industrial channels of distribution. J. Bus. Res. 40(2) 139-154.

Kim, Namwoon, Vijay Mahajan, Rajendra K. Srivastava. 1995. Determining the going market value of a business in an emerging information technology industry: The case of the cellular communications industry. Tech. Forecasting Soc. Change 49 257-279.

Knott, Aaron, Andrew Hayes, Scott Neslin. 2002. Next-product-tobuy models for cross-selling applications. J. Interactive Marketing 16(3).

Kumar, Nirmalya, Lisa K. Sheer, Jan-Benedict E. M. Steenkamp. 1995. The effects of supplier fairness on vulnerable resellers. J. Marketing Res. 32(Feb.) 54-65.

Lal, Rajiv, David E. Bell. 2003. The impact of frequent shopper programs in grocery retailing. Quant. Marketing Econom. 1(2) 179-202.

Leenheer, Jorna, Tammo Bijmolt, Harald van Heerde, Ale Smidts. 2003. Do loyalty programs enhance behavioral loyalty? A market-wide analysis accounting for endogeneity. Working paper, Tilburg University, Tilburg, The Netherlands.

Lemmens, Aurélie, Christophe Croux. 2005. Bagging and boosting classification trees to predict churn. J. Marketing Res. 43(2) 276-286.

Lewis, Michael. 2003. Customer acquisition promotions and customer asset value. Working paper, University of Florida, Gainesville, FL.

Lewis, Michael. 2005a. A dynamic programming approach to customer relationship pricing. Management Sci. 51(6) 986-994.

Lewis, Michael. 2005b. Incorporating strategic consumer behavior into customer valuation. J. Marketing 69(4) 230-238.

Li, Shibo, Baohong Sun, Ronald Wilcox. 2005. Cross-selling sequentially ordered products: An application to consumer banking services. J. Marketing Res. 42(2) 233-239. 
Libai, Barak, Eitan Muller, Renana Peres. 2005. The diffusion of services. Working paper, Tel Aviv University, Tel Aviv, Israel.

Loveman, Gary. 1998. Employee, satisfaction, customer loyalty, and financial performance: An empirical examination of the service profit chain in retail banking. J. Service Res. 1(1) 18-31.

Loveman, Gary. 2003. Diamonds in the data mine. Harvard Bus. Rev. 81(May) 109-113.

MacKenzie, Scott B., Philip M. Podsakoff, Michael Ahearne. 1998. Some possible antecedents and consequences of in-role and extra-role salesperson performance. J. Marketing 62(July) 87-98.

Malthouse, Edward, Robert Blattberg. 2005. Can we predict customer lifetime value? J. Interactive Marketing 19(1) 2-16.

Manchanda, Puneet, Asim Ansari, Sunil Gupta. 1999. The shopping basket: A model for multicategory purchase incidence decisions. Marketing Sci. 18(2) 95-114.

Manchanda, Puneet, J.-P. Dube, Khim-Yong Goh, Predeep Chintagunta. 2005. The effects of banner advertising on consumer inter-purchase times and expenditures in digital environments. J. Marketing Res.

Mattila, Anna S. 2001. The impact of relationship type on customer loyalty in a context of service failures. J. Service Res. 4(4) 91-101.

Mazursky, David, Aviva Geva. 1989. Temporal decay in satisfaction-intention relationship. Psych. Marketing 6(3) 211-227.

McLaughlin, John P. 1993. Ensuring customer satisfaction is a strategic issue, not just an operational one. Present. AIC Customer Satisfaction Measurement Conf., Chicago, IL (Dec. 6-7).

Mittal, Vikas, Wagner Kamakura. 2001. Satisfaction, repurchase intent, and repurchase behavior: Investigating the moderating effect of customer characteristics. J. Marketing Res. 38(1) 131-142.

Mittal, Vikas, Pankaj Kumar, Michael Tsivos. Attribute-level performance, satisfaction, and behavioral intentions over time: A consumption-system approach. J. Marketing 63(2) 88-101.

Mittal, Vikas, Eugene Anderson, Akin Sayrak, Pandu Tadikamalla. 2005. Dual emphasis and the long-term financial impact of customer satisfaction. Marketing Sci. 24(4) 531-543.

Moorman, Christine, Gerald Zaltman, Rohit Deshpande. 1992. Relationships between providers and users of market research: The dynamics of trust within and between organizations. J. Marketing Res. 29(Aug.) 314-329.

Morgan, Robert, Shelby D. Hunt. 1994. The commitment-trust theory of relationship marketing. J. Marketing 58(July) 20-38.

Morwitz, Vicki, Eric Johnson, David Schmittlein. 1993. Does measuring intent change behavior? J. Consumer Res. 20(June) 46-61.

Morwitz, Vicki, David Schmittlein. 1992. Using segmentation to improve sales forecasts based on purchase intent: Which "Intenders" actually buy? J. Marketing Res. 29(November) 391-405.

Nayyar, Praveen. 1995. Stock market reactions to customer service changes. Strategic Management J. 16(1) 39-53.

Nelson, Eugene, Ronald Rust, Anthony Zahorik, Robin Rose, Paul Batalden, Beth Ann Siemanski. 1992. Do patient perceptions of quality relate to hospital financial performance? J. Health Care Marketing December 6-13.

Neslin, Scott, Sunil Gupta, Wagner Kamakura, Junxiang Lu, Charlotte Mason. 2006. Defection detection: Measuring and understanding the predictive accuracy of customer churn models. J. Marketing Res. 43(2) 204-211.

Ngobo, Paul Valentin. 1999. Decreasing returns in customer loyalty: Does it really matter to delight customers. L. Scott, F. Arnould, eds. Advances in Consumer Research. Association for Consumer Research, Valdosta, GA, 469-476.

Niraj, Rakesh, Mahendra Gupta, Chakravarthi Narasimhan. 2001. Customer profitability in a supply chain. J. Marketing 65(July) $1-16$.

Oliver, Richard. 1993. Cognitive, affective, and attribute bases of the satisfaction response. J. Consumer Res. 20(Dec.) 418-430.

Oliver, Richard. 1997. Satisfaction: A Behavioral Perspective on the Consumer. McGraw-Hill, New York.

Parasuraman, A., Valarie A. Zeithaml, Leonard L. Berry. 1988. SERVQUAL: A multiple-item scale for measuring consumer perceptions of service quality. J. Retailing 64(Spring) 12-40.

Parasuraman, A., Valarie A. Zeithaml, Leonard L. Berry. 1994. Reassessment of expectations as a comparison standard in measuring service quality: Implications for further research. J. Marketing 58(Jan.) 111-124.

Pfeifer, Phillip, Robert Carraway. 2000. Modeling customer relationships as Markov chains. J. Interactive Marketing 14(2) 43-55.

Reichheld, Frederick F. 1996. The Loyalty Effect. Harvard Business School Press, Boston, MA.

Reichheld, Frederick F. 2003. The one number you need. Harvard Bus. Rev. 81(12) 46-54.

Reichheld, Frederick F., W. Earl Sasser, Jr. 1990. Zero defections: Quality comes to services. Harvard Bus. Rev. (Sept.-Oct.) 105111.

Reinartz, Werner, V. Kumar. 2000. On the profitability of long-life customers in a noncontractual setting: An empirical investigation and implications for marketing. J. Marketing 64(Oct.) 17-35.

Reinartz, Werner, V. Kumar. 2003. The impact of customer relationship characteristics on profitable lifetime duration. J. Marketing 67(1) 77-99.

Reinartz, Werner, Jacquelyn Thomas, V. Kumar. 2005. Balancing acquisition and retention resources to maximize customer profitability. J. Marketing 69(1) 63-79.

Reynolds, Kristy, Mark Arnold. 2000. Customer loyalty to the salesperson and the store: Examining relationship customers in an upscale retail context. J. Personal Selling Sales Management 20(2) 89-99.

Roy, Soumya. 1999. Case of a pharmaceutical company: Using business outcomes modeling to build customer loyalty. Gallup Consulting Group. Princeton, NJ.

Rucci, Anthony, Steven Kirn, Richard Quinn. 1998. The employeecustomer-profit chain at Sears. Harvard Bus. Rev. (Jan.-Feb.) 83-97.

Rust, Roland, Anthony Zahorik. 1993. Customer satisfaction, customer retention, and market share. J. Retailing 69(2) 193-215.

Rust, Roland, Katherine Lemon, Valarie Zeithaml. 2004. Return on marketing: Using customer equity to focus marketing strategy. J. Marketing 68(1) 109-126.

Rust, Roland, Anthony Zahorik, Timothy Keiningham. 1995. Return on quality (ROQ): Making service quality financially accountable. J. Marketing 59(April) 58-70.

Sasser, W. Earl, Jr., R. Paul Olsen, D. Daryl Wyckoff. 1978. Management of Service Operations: Text and Cases. Allyn \& Bacon, Boston, MA.

Schmittlein, David, Robert Peterson. 1994. Customer base analysis: An industrial purchase process application. Marketing Sci. 13(1) 41-68.

Schmittlein, David, Donald Morrison, Richard Colombo. 1987. Counting your customers: Who are they and what will they do next? Management Sci. 33(1) 1-24.

Selnes, Fred, Kjell Gonhaug. 2000. Effects of supplier reliability and benevolence in business marketing. J. Bus. Res. 49(3) 259-270.

Sharp, Byron, Anne Sharp. 1997. Loyalty programs and their impact on repeat-purchase loyalty patterns. Internat. J. Res. Marketing 14(5) 473-486.

Shugan, Steven M. 2005. Editorial: Brand loyalty programs: Are they shams? Marketing Sci. 24(2) 185-193.

Simester, Duncan, Peng Sun, John Tsitsiklis. 2006. Dynamic catalog mailing policies. Management Sci. 52(5) 633-696. 
Sirdeshmukh, Deepak, Jagdip Singh, Barry Sabol. 2002. Consumer trust, value and loyalty in relational exchanges. J. Marketing 66(Jan.) 15-37.

Tellis, Gerald. 1988. Advertising loyalty, exposure and brand purchase: A two-stage model of choice. J. Marketing Res. 25(2) 134-145.

Thomas, Jacquelyn. 2001. A methodology for linking customer acquisition to customer retention. J. Marketing Res. 38(2) 262-268.

Thomas, Jacquelyn, Robert Blattberg, Edward Fox. 2004. Recapturing lost customers. J. Marketing Res. 16(Feb.) 31-45.

Thomas, Jacquelyn, Werner Reinartz, V. Kumar. 2004. Getting the most out of all your customers. Harvard Bus. Rev. 82(July-Aug.) $116-123$.

Tse, David K., Peter C. Wilton. 1988. Models of consumer satisfaction formation: An extensive. J. Marketing Res. 25(2) 204-212.

Venkatesan, Rajkumar, V. Kumar. 2004. A customer lifetime value framework for customer selection and resource allocation strategy. J. Marketing 68(4) 106-125.

Verhoef, Peter, Philip Hans Franses, Janny C. Hoekstra. 2001. The impact of satisfaction and payment equity on cross-buying: A dynamic model for a multi-service provider. J. Retailing 77(3) 359-378.
Verhoef, Peter, Philip Hans Franses, Janny C. Hoekstra. 2002. The effect of relational constructs on customer referrals and number of services purchased from a multiservice provider: Does age of relationship matter? J. Acad. Marketing Sci. 30(3) 202-216.

Woodside, Arch, Lisa Frey, Robert Daly. 1989. Linking service quality, customer satisfaction, and behavior. J. Health Care Marketing 9(4) 5-13.

Yi, Youjae. 1990. A critical review of consumer satisfaction. Valarie A. Zeithaml, ed. Review of Marketing. American Marketing Association, Chicago, IL.

Yoo, Shijin, Dominique Hanssens. 2005. Modeling the sales and customer equity effects of the marketing mix. Working paper, UCLA, Los Angeles, CA.

Zeithaml, Valarie A. 1988. Consumer perceptions of price, quality, and value: A conceptual model and synthesis of research. J. Marketing 52(July) 2-22.

Zeithaml, Valarie A., A. Parasuraman. 2004. Service Quality. MSI Relevant Knowledge Series, Cambridge, MA.

Zeithaml, Valarie A., Leonard L. Berry, A. Parasuraman. 1996. The behavioral consequences of service quality. J. Marketing 60(April) 31-46. 